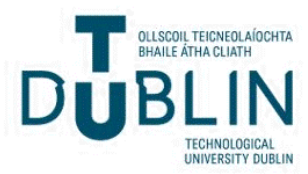

Technological University Dublin ARROW@TU Dublin

2014

\section{Active Confinement of Weakened Concrete Columns}

\author{
Niall Holmes \\ Technological University Dublin, niall.holmes@tudublin.ie \\ Dervilla Niall \\ Technological University Dublin, dervilla.niall@tudublin.ie \\ C. O'Shea \\ Technological University Dublin
}

Follow this and additional works at: https://arrow.tudublin.ie/engschcivart

Part of the Civil Engineering Commons, and the Construction Engineering and Management Commons

\section{Recommended Citation}

Holmes, N., Niall, D. \& O'Shea, C. (2014) Active confinement of weakened concrete columns, Materials and Structures, June, 2014. doi:10.1617/s11527-014-0352-1

This Article is brought to you for free and open access by the School of Civil and Structural Engineering at ARROW@TU Dublin. It has been accepted for inclusion in Articles by an authorized administrator of ARROW@TU Dublin. For more information, please contact arrow.admin@tudublin.ie, aisling.coyne@tudublin.ie, gerard.connolly@tudublin.ie.

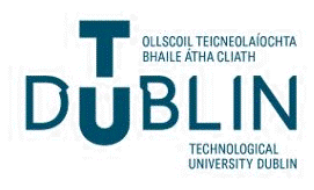




\section{ACTIVE CONFINEMENT OF WEAKENED CONCRETE COLUMNS}

N. Holmes*, D. Niall \& C. O’Shea

Dublin Institute of Technology,

School of Civil \& Structural Engineering,

Bolton Street,

Dublin 1,

Ireland.

Phone: +353 14022914

Email: niall.holmes@dit.ie

*Corresponding Author 


\begin{abstract}
This paper investigates the advantages of using of external active confinement to improve the compression load capacity of concrete cylinders using mild steel band clamps. For this, passive and actively pre-stressed steel bands have been attached to concrete cylinders to mimic real structural columns which may otherwise have to be removed and replaced due to poor strength performance.
\end{abstract}

The experimental programme included compression load testing a number of unreinforced concrete cylindrical specimens to establish the effect the confinement had on the compressive load-carrying capacity and the stress-strain behaviour. A number of parameters were investigated in the study including the effect of varying the band spacing, volumetric ratio and passive and active confining forces.

It was found that confining the concrete did produce an increase in compressive strength. However, the different levels of pre-stress used had no significant effect on strength but did influence the confined concrete stress-strain behaviour with greater lateral stresses at peak strength observed. Ductility increases were observed for confined specimens and significant axial strains achieved with noticeable peak strength enhancements. However, due to initial misfit between the bands and the concrete in the passive confinement state, confining forces generated only contained the cracked specimens. The actively pre-stressing confinement yielded an increase in load capacity of $53 \%$ as the bands were fully activated.

KEYWORDS: concrete cylinders; active confinement; prestress; steel bands; ductility; strength 


\section{NOTATION}

$E_{s} \quad$ Modulus of elasticity of transverse reinforcement (MPa)

$f^{\prime}{ }_{c c} \quad$ Compression strength of confined concrete (MPa)

$f_{h}^{\prime} \quad$ Stress in confinement reinforcement at peak strength (MPa)

$f_{c} \quad$ Stress acting on confined concrete (MPa)

$f_{\text {co }} \quad$ Concrete cylinder compression strength $\left(\mathrm{N} / \mathrm{mm}^{2}\right)$

$f_{h} \quad$ Stress in confinement reinforcement (MPa)

$f_{\text {hy }} \quad$ Yield strength of transverse reinforcement (MPa)

$I_{e}^{\prime} \quad$ Effective confinement index evaluated at peak strength

$I_{e} \quad$ Effective confinement index

$I_{\text {e50 }} \quad$ Effective confinement index evaluated at $\varepsilon_{\mathrm{cc} 50}$

$k_{1}, k_{2} \quad$ Parameters controlling shape of post-peak portion of stress-strain curve

Spacing between ties (mm)

$\delta_{H} \quad$ Gap width (mm)

$\varepsilon_{c c} \quad$ Axial strain at peak strength of confined concrete

$\varepsilon_{c} \quad$ Axial strain in confined concrete

$\varepsilon_{c c 50} \quad$ Post-peak axial strain in confined concrete when capacity drops to $50 \%$ of confined strength

$\varepsilon_{c o} \quad$ Axial strain corresponding to concrete cylinder strength

$\varepsilon_{c o 50} \quad$ Post-peak axial strain in unconfined concrete when capacity drops to $50 \%$ of unconfined strength

$\kappa$

Parameter used to determine if yielding of transverse reinforcement occurs at peak strength of confined concrete

$\rho_{c c} \quad$ Ratio of longitudinal to lateral reinforcement

$\rho_{s} \quad$ Effective volumetric ratio of transverse reinforcement

$\rho_{\text {sey }} \quad$ Effective sectional ratio of confinement reinforcement in $y$ direction 
$A_{H} \quad$ Area of transverse reinforcement within spacing s $\left(\mathrm{mm}^{2}\right)$

$\mathrm{d}_{\mathrm{s}} \quad$ Diameter of spiral or hoop between bar centres $\left(\mathrm{mm}^{2}\right)$

$f^{\prime} l \quad$ Effective confinement stress (MPa)

$f_{1} \quad$ Effective lateral confining pressure (MPa) 


\section{INTRODUCTION}

Rehabilitation of existing reinforced concrete columns may be required for a number of reasons. Many older buildings require rehabilitation and structural strengthening to allow for continued service if a change in the use or occupancy is planned or to improve the load carrying capacity caused by deficient concrete as evidenced by low cube strength results. In the case of the latter, the structural column may need to be removed and re-placed leading to significant financial costs and time implications. Therefore, the most practical solution to lessen the risk of structural collapse is by external strengthening.

Significant advances in the understanding of structural behaviour have occurred over the past 40 years. However, the lack of strict design criteria for older and deficient concrete elements has made them particularly susceptible to failure. A common detailing problem found in older reinforced concrete columns is widely spaced transverse ties or links. This leads to poor confinement and support to longitudinal reinforcement required to delay the strength degradation of concrete under ultimate load conditions and allow a ductile response. Failure of a column can be catastrophic and may cause partial or even complete structural collapse.

Column confinement to improve their structural performance can be applied using externally applied transverse reinforcement configurations such as jackets, collars, straps or wraps which can offset significant material and labour costs as well as the disruption of the use and operation of the structure.

A particularly innovative avenue of research in this area is the employment of active confinement. Where passive confinement relies on dilating concrete upon loading to initiate the generation of confining pressures, active confinement applies an initial confining pressure by pre-stressing the material making it more effective. The effect of confinement is typically expressed by the volumetric ratio $\left(\rho_{s}\right)$ which is the relationship between transverse reinforcement to the concrete core.

This study examines the effect of active confinement on the behaviour of concrete in compression. A simplified technique is adopted to apply the prestress forces onto the concrete using band clamps. Three primary parameters are investigated in order to establish their effects on overall strength and ductility namely, the effect of passive confinement, varying 
the band spacing and the impact of different pre-stress levels on the load-carrying capacity in compression.

\section{CONCRETE CONFINEMENT}

A major issue with older concrete columns is the lack of lateral confinement. As weaker concrete structural members, particularly columns confined by ties or spirals react to Poisson type lateral expansion, an increase in the extent and coverage of lateral steel around the concrete will improve the ductility and strength.

Confinement can be divided into two types, passive and active. The former refers to lateral reinforcement reacting to concrete lateral expansion which causes a confinement pressure under loading due to Poisson's effect and micro-cracking (Shin and Andrawes, 2010). In active confinement the confining pressure applied to prestress the element laterally prior to loading, exerts a small lateral stress on the concrete with the result being an increase in the load capacity (Shin and Andrawes, 2010).

The major difference between passive and active confined concrete is the lateral pressure exerted on the section prior to axial loading, as illustrated in Figure 1. Confinement in reinforced concrete columns is usually provided by a combination of longitudinal bars tied with lateral reinforcement in the form of circular hoops or spirals, steel jackets, fibre reinforced polymers, textile reinforced mortars, fibre ropes and steel reinforced grout. The area enclosed by the lateral reinforcement is referred to as the concrete core.

A review of these methods is presented below.

\subsection{Reinforced concrete jackets}

Jackets can be applied to all or part of the column. This method is very effective for enhancing the strength, stiffness and ductility and is recommended for severely damaged columns. However, In structures where refurbishment or a change in use is planned and improvements to the load carrying capacity of existing columns is required, the technique of 
applying exterior reinforcement depends on the optimum global intervention strategy for the specific building (Fardis, 2009).

\subsection{Steel jackets}

This technique fixes thin steel plates (steel encasement) or tie plates (steel cage) around the column with steel angles at each corner, clamped to the concrete and welded together. Adequate tightening of the jackets can be ensured by means of heat tensioning.

The use of steel jackets can enhance the shear strength of columns considerably. However, due to their low flexural stiffness (as with most retrofit techniques) they typically have poor confinement efficiency for square and rectangular columns. This limits the effectiveness of the system for increasing the deformability of the columns.

\subsection{Spiral Reinforcement}

This technique consists of mild steel fixed around the damaged element which are heated and hammered in situ to form a spiral. They can be welded onto steel angles fixed on the corners. Heating of the bars is essential to ensure that they are effectively conformed to the existing column interface in order to generate confining forces.

\section{$2.4 \quad$ High strength fibre composites (FRP)}

High strength fibre composites are used as an alternative to steel jacketing. The high strength fibre is saturated in a special epoxy solution which allows them to be wrapped around columns and structural members. FRP jackets are more effective in confining circular columns because the fibres create a uniform confining pressure in circular columns which is a function of the hoop strength of the jacket. The confining pressure for square cross sections is not as effective as it varies from maximum at the corners to minimum at the centre which does not conform well with the low flexural rigidity of the FRP composite. However, the use of unstressed high strength fibre composite jackets can enhance the ductility and increase the shear strength of columns to the extent that brittle shear failures can be avoided. 


\subsection{Steel collars}

Steel collar ties are placed around the column and are densely spaced over the damaged area. Corners of existing columns are protected by steel angles and a light wire mesh is placed on all four edges with a gunite jacket of at least $50 \mathrm{~mm}$. As the collars are screw tightened, the tension force in the steel collar exerts an active confining stress on the column. Externally collared columns can exhibit an improved performance compared to conventionally reinforced ones as the area of confined concrete is increased and spalling can be prevented. By increasing the collar spacing, the confinement effectiveness is reduced.

The active pressure can improve the load carrying capacity up to peak load but increases post-peak degradation due to rapid spalling of the concrete in between.

\subsection{Review of current retrofitting techniques}

Concrete jacketing is considered to be one of the most effective methods to repair and rehabilitate concrete columns. Rodriguez and Park (1994) demonstrated that it is an effective technique to enhance the strength, stiffness and ductility of the concrete column. However, while the rehabilitation technique has proven to be effective it is extremely labour intensive. In order to ensure proper bond of the jacket, the surface of the existing column requires roughening and extensive cleaning to ensure that all damaged concrete is removed. In addition it requires drilling into the existing column to allow passage of added reinforcement in the concrete jacket. The increased labour results in a high cost and considerable disruption to building use during application. Increases in the dimensions of the column after application can also be a limitation to its use.

According to Xiao and $\mathrm{Wu}$ (2003), when ductility is the main factor in repair and rehabilitation of a specific member, the steel jacketing method is most efficient. The drawbacks of using steel jacketing include the quality assurance required with welding to ensure an adequate bond is created with the concrete interface. The technique of externally applying spiral reinforcement through heat treatment and hammering has similar drawbacks to steel jacketing. 
The two main disadvantages associated with the use of FRP reported by Mirmiran and Shahawy (1998) are the high costs involved in their production and the lack of pretension in the fibres which inhibits its full utilisation. In a similar manner the use of square collars is limited by its shape and by the cost of manufacture of the collared pieces. Work on fibre reinforcement strengthening using jackets by Yan et al (2007) has shown they are more effective in circular columns than square or rectangular sections following experiments on shape-modified concrete columns using post-tensioned FRP shells. The authors found that this arrangement did alter the confinement from a passive to an active state with improved axial and ultimate compressive axial strain capacities of both.

Valdmanis et al (2007) analysed the mechanical behaviour of concrete confined by carbon fibre-reinforced polymer (CFRP) sheets. The authors concluded that a reduction of 0.50 should be applied to the CFRP tensile strength in the ultimate strength approach to obtain accurate strength predictions.

Janke et al (2009) found that pre-stressed external confinement of concrete compression members improved the concretes residual capacity and was particularly effective in cyclic loading tests compared to the unstressed case.

Tamuzs et al (2006) investigated the mechanical behaviour of concrete cylinders confined with carbon-fibre epoxy tapes with different thickness and pre-stress levels subject to monotonic compressive loading. They found a non-linear stress-strain behaviour with significant ductility and increases in ultimate strength. Above the ultimate strength, increased damage and plastic deformations occurred evidenced by pronounced residual strains.

Rousakis and Tourtouras (2014) studied the effect of high extension capacity fibre ropes as a means of externally confining reinforcement in square plain or reinforced concrete columns. The results demonstrated that the novel technique performed satisfactorily under loading with high pretension levels possible without friction between the external wrapping and the concrete. However, after the ropes were unwrapped following testing, extensive cracking of the concrete core was detected along with buckling of multiple steel bars. Notwithstanding this, all strengthened reinforced concrete columns presented improved stress-strain behaviour 
with a restriction of premature buckling of the slender bars with a prolongation of the elastic response of the column by $40 \%$ in terms of load.

The following will introduce a new method, albeit for small scale concrete cylinders, to apply an active prestress to improve their load-carrying capacity using a number of steel band clamps at multiple locations. 


\subsection{Concrete samples and mix proportions}

Twelve concrete cylinders, each 150mm diameter and 300mm long were cast using CEM I cement (BS EN 197, 2000). The concrete was designed to achieve a characteristic strength $\left(f_{c k}\right)$ of $30 \mathrm{~N} / \mathrm{mm}^{2}$ at 28 days with a w/c ratio of 0.47 , which achieved a mean strength of $25 \mathrm{~N} / \mathrm{mm}^{2}$ at 7 days using a trial mix. The quantities of the designed concrete mix are shown in Table 1. To investigate the effect of deficient concrete in terms of compressive strength so the influence of confinement could be observed, following a number of trial mixes, an additional $87 \mathrm{~kg} / \mathrm{m}^{3}$ or 5 litres of water (based on a concrete volume of $0.07 \mathrm{~m}^{3}$ ) was added to the mix to increase the w/c ratio to 0.67 . The designed slump was between $30-60 \mathrm{~mm}$ which increased due to the additional water. No additives were used.

\subsection{Preparation of concrete samples}

The concrete specimens were cast in three $100 \mathrm{~mm}$ depths in cylindrical steel moulds with a release agent to ease de-moulding the following day. Each level was compacted with a poker vibrator. The tops of the cylinders were prepared with a mortar cap (3:1 sand to cement mix) to ensure a level surface when the vertical compression loads where applied during testing to remove any load eccentricity. The mortar was compacted and a glass capping plate pressed against the mould using a rotary hand motion until a horizontal surface was achieved. The glass cap was left in position until the steel mould was removed. Previous work by Valdmanis et al (2007) used teflon sheets inserted between concrete and steel bearing platens to reduce friction.

Curing of the concrete was provided by placing the cylinders under polythene sheets for 24 hours after mixing. The cylinders were removed from the moulds the following day and

placed into a curing tank at $20 \pm 2^{0} \mathrm{C}$. After 6 days, they were removed and prepared for testing the following day. This curing time would be typical for structural columns. Furthermore, at 7 days, the first set of concrete cube results would be returned to site and upon discovering the deficient concrete strength; a decision to remove the affected member or somehow retain it with external strengthening would have to be made with the latter investigated here. 


\subsection{Fresh concrete properties}

The workability of the concrete was measured in terms of slump, noted immediately after manufacture, in accordance with BS EN 12350-2 (2009).

\subsection{Preparation of samples for testing}

\subsubsection{Selection of confinement mechanism}

As discussed previously, many innovative methods have been studied to simplify the application of pre-stress in retro-fitting structures such as shape memory alloys. As these can be quite expensive to employ, more economical alternatives were explored.

When considering a retrofit method, ease of application is a key factor. To apply bands and pre-stress them with bolts or threaded couplings, the band must be in half pieces for placing around existing columns. Therefore, a super hose clamp (W1) by Mikalor was chosen. As shown in Figure 2, it consists of a mild steel band with a grade 8.8 bolt for applying torque and a yield strength of 177.17MPa. As a practical retrofit method this band would not suffice as the opening required to place the band around the column would create large bending stresses and possible local yielding. However, for the samples analysed here, this band could demonstrate the desired 'active' confinement effect, simply applied, and imposing the required lateral pressure in a relatively uniform manner.

Rousakis (2013) used FRP sheets made from glass fibres and polypropylene fibre ropes (PPFRs). The hybrid confinement technique avoided the need for impregnation or applying gluing resins and applied the lateral confinement uniformly around the concrete cylinders tested. Similarly, Rousakis (2014) examined the effect of low modulus vinylon and polypropylene fibre ropes as external confinement. The technique was found to improve the plain concrete strength by a factor of 6.6 with no column reaching fracture. The polypropylene fibre ropes were applied by hand without any mechanical means or stretching and provides an equal lateral pressure around the concrete, as shown in Figure 3. 


\subsubsection{Preliminary Testing}

A preliminary study of the band force during tensioning was carried out where the hoop stress around the circumference was determined using strain gauges fitted at three points around the band, $90^{\circ}$ to each other as shown in Figure 4 . The band was finger tightened around the concrete and strain readings were taken as the torque increased in increments up to a maximum of $50 \mathrm{Nm}$ as specified by the manufacturer using a calibrated torque wrench.

Shortly after, it was clear the band had undergone yielding before the maximum torque of $50 \mathrm{Nm}$ was achieved as the strain readings around it exceeded the assumed yield strain of 1250 micro strain $\left(\mu_{\mathrm{s}}\right)$. This was due to the frictional force between the concrete and the band causing the clamp to yield prematurely as it reconfigured itself around the circumference of the concrete cylinder. To reduce this effect, the concrete cylinders were wrapped in electrical tape at the band locations and plumbing grease applied between both to decrease the frictional force as relative movement between them was now permitted.

The electrical tape also helped reduce the friction between the cylinder and the steel bands which can prevent concrete expanding transversally leading to differing effects along the cylinder. Teflon sheets can also be used between the concrete surface and steel bands to remove this friction giving an improved response during the test. The bending of the band can also cause end friction which reduces the vertical compressive deformation at mid height and can lead to a reduction in the measured Young’s Modulus (Tepfers, 2012).

The initial strain results indicated a non-uniform distribution of radial forces throughout the band. Therefore, a theoretical analysis of the radial stresses was carried out to determine the hoop stresses and the corresponding confining pressures in terms of band elongation. Stresses were derived in two stages; initial bending stresses as it closed around the cylinder and radial stresses, related to changes in gap width $\left(\delta_{H}\right.$ once the torque was applied, as shown in Table 2 and Figure 5.

To determine the applied confining force, the bands were finger tightened and the initial gap between them and the concrete was recorded using vernier callipers. Specific changes in gap width $\left(\delta_{H}\right)$ were then applied to the bands and a relationship between it and the confining pressure was developed (Table 2; Figure 5). 


\subsection{Test set-up.}

Specimens were divided into four series as follows:

\subsubsection{Test Series 1 - Unconfined.}

The first test series consisted of determining the compressive strength of the four unconfined specimens with the additional water content at 7 days. These samples were simply placed in the compressive testing machine to obtain the unconfined cylinder strength of the concrete. The cylinders were each fitted with a longitudinal and a lateral strain gauge (Figure 6) so the unconfined stress-strain curve could be plotted as well as determining the average compression strength. The strain gauges used were manufactured by Tokyo Sokki Kenkyujo Ltd, of gauge type YFLA, $5 \mathrm{~mm}$ long with a gauge factor of $2.10 \pm 2 \%$.

\subsubsection{Test Series 2 - Passive}

This test series consisted of applying four band clamps to the sample with an equal spacing of $56 \mathrm{~mm}$ along the length and a $10 \mathrm{~mm}$ gap top and bottom to ensure the bands were not directly loaded from above. The test setup is shown in Figure 11.

The cylinder was wrapped in tape at the band locations and greased to reduce frictional effects as discussed. The initial prestress applied was minimum (finger tightened) so as to demonstrate "passive” confinement. Longitudinal and lateral strain gauges were placed in the centre of the specimen between bands in order to obtain a passive specimen stress-strain curve.

\subsubsection{Series 3 - Constant prestress; varying spacing}

In the third test series, three band clamps were applied to the sample with spacing's of 150, 96 and 56mm with two, three and four straps respectively and a $10 \mathrm{~mm}$ gap top and bottom as before. An initial prestress of 2.66MPa was applied to each band corresponding to level two in Figure 9. This test series determined the effect of spacing and changes in the volumetric ratio (ratio of lateral reinforcement area to concrete core) on the peak compressive stress of confined concrete. The test setup is shown in Figure 12. 


\subsubsection{Series 4 - constant spacing; varying prestress}

The fourth test series consisted of applying three band clamps to three samples at four locations with 56mm spacing's (Figure 13). This series was set up to assess the effect of active confining pressures (shown in Figure 9) on the peak compressive stress of confined concrete.

\subsubsection{Specimen Testing}

The compressive load was applied using a cube crushing machine with a capacity of $3,000 \mathrm{kN}$ at an average rate of $0.3 \mathrm{MPa} / \mathrm{s}$ and within the $0.14-0.34 \mathrm{MPa} / \mathrm{s}$ level recommended by ASTM C39 (2004).

\section{EXPERIMENTAL RESULTS}

4.1 Fresh and hardened concrete results

A measured slump of 143mm was recorded using the standard test (BS EN 12350-2, 2009).

\subsection{Specimen load testing}

The specimens were subject to axial compressive loads at 7-days using a cube crushing machine. The load was increased based on a displacement-controlled strategy until failure of the specimens occurred.

\subsection{Series 1 - Unconfined}

The results from the four unconfined compressive strengths test at 7-days (Test Series 1) are shown in Figure 14. As may be seen, the samples had an average strength of $14.18 \mathrm{~N} / \mathrm{mm}^{2}$ which is much less than the characteristic strength of 30MPa. This reduction in strength is due to the additional water added to mimic the effect of deficient concrete in terms of low compressive strength. 
The stress-strain graph obtained from these results is incomplete past an axial strain of 0.0007 (averaged in Figure 16) as the strain gauge failed due to cracking of the outer surface (Figure 15) at the gauge location. Therefore, in order to obtain an estimate of the peak axial strain of 0.0015 at the peak compressive stress, a theoretical formula proposed by Legeron and Paultre (2003) (Equation 1) was used. This equation is based on the unconfined compressive stress where $\varepsilon_{c o}$ is the axial strain corresponding to concrete cylinder strength and $f_{c o}$ is the concrete cylinder compression strength (MPa). The initial Poisson's ratio for the concrete was determined by relating lateral strain to axial strain in Figure 17 and was calculated to be 0.1856, and within the standard limits of $0.17-0.22$ for concrete.

$$
\varepsilon_{\mathrm{co}}=0.0005\left(\mathrm{f}_{\mathrm{co}}\right)^{0.4}
$$

Equation 1

\subsection{Series 2 - Passive}

The stress-strain results from the finger tightened steel bands following loading are shown in Figure 18(a). As shown, a peak compressive stress of 14.03MPa was obtained. It was noted before testing that due to finger tightening only, the band did not fully conform to the shape of the cylinder due to areas of misfit around the circumference. This misfit allowed the concrete to behave as if it were unconfined until it dilated at which point the bands take effect as they only contain cracked concrete instead of delaying the onset of crack formation. As a result, there is no obvious increase in compressive strength.

As may be seen by the extent of the cracks in Figure 18(b), the specimen did resist strength degradation, unlike the unconfined specimen. The mode of failure differed from the unconfined concrete, where cracks formed normal to the vertical axis in between bands and crushing occurred perpendicular to the direction of loading.

\subsection{Series 3 - Constant prestress; varying spacing}

As shown in Figure 19, when the spacing between bands decreases, there is an increase in compressive strength due to the increased volumetric ratio. There is also a corresponding increase in peak strain as shown in Figure 20. The results from the $96 \mathrm{~mm}$ band spacing are inconsistent and are considered to be due to a problem with the strain gauge during testing. 
It is clear from the stress-strain relationships (Figure 20) that the point of unstable crack propagation (corresponding to the critical stress of concrete) occurs at a higher stress. As the band spacing decreases, the mode of failure is primarily due to crushing of the concrete in between (Figure 21).

The compression results with the 150mm band spacing did not exhibit an increase in strength. This correlates with findings from Iyengar et al (1970) who found that with a confining band spacing equal to the diameter of the cylinder, diagonal cracks will occur in-between.

\subsection{Series 4 - Constant spacing; varying prestress}

The results from Test Series 4 with active prestress applied to the bands (see Figure 9) show an average improvement in compression load capacity of 53\% (Figure 22). Figure 23 demonstrates a difference between the peak strains recorded for those specimens subjected to pre-stress levels 2 and 3 (see Figure 9). While they did obtain similar peak stresses, the specimen corresponding to prestress Level 3 did so at a smaller peak strain with some level of stiffness deterioration beginning at approximately 12MPa. Due to the higher maximum stress, an enhanced stress-strain behaviour would be expected. Moghaddam et al (2010a) and Moghaddam et al (2010b) found significant increases in the strength and ductility of specimens confined with metal strips which was contributed to the volumetric ratio of the active confinement. They observed stiffer pre-peak responses of the concrete cylinder specimens than un-confined un-pre-stressed samples. Improved stress-strain behaviour was observed by Rousakis Tourtouras (2014) in RC square columns confined using high extension capacity fibre ropes externally undergoing multiple seismic cycles of increasing compressive deformation. The authors found enhanced stress-strain behaviour and by pretensioning the external confinement, the elastic response of the columns was prolonged by $40 \%$ in terms of load with an improved inelastic stress-strain modulus.

Despite the specimen here reaching its peak compressive stress, the strain readings indicate it did so with considerably more internal damage. The mode of failure here is excessive crushing of the concrete in between the bands evident in the specimen corresponding to prestress Level 2 in Figure 24. The strength enhancement from Series 3 and 4 are shown in Table 3 compared to the unconfined average. 


\section{ANALYTICAL MODEL}

An analytical model was developed to compare with the experimental results above and to predict the behaviour of confined axially loaded concrete columns. The model used is based on the work by Legeron and Paultre (2003) capable of tracing the behaviour throughout the loading history and calculating peak compressive stress and strain. It is a progression from Cusson and Paultre (1995) where the behaviour of confined concrete is related to a nondimensional parameter $I_{e}$, based on strain compatibility and transverse force equilibrium taking account of confinement reinforcement, spatial distribution of the reinforcement, concrete strength and reinforcement yield strength.

The step by step method proposed by Legeron and Paultre (2003) to predict the response of a confined column to concentric compression is summarised below:

1. Determine the confinement effectiveness coefficient, $k_{e}=\frac{\left(1-\frac{s}{s d_{s}}\right)^{2}}{1-\rho_{c c}}$

2. Determine the volumetric ratio of transverse reinforcement to confined concrete core, $\rho_{s}=\frac{4 A_{H}}{d_{S} S}$

3. Determine the effective volumetric ratio, $\rho$ sey $=\frac{1}{2} \rho_{s} f_{h}$

4. Calculate $\kappa$ (determines if yielding of transverse reinforcement occurs at peak confined concrete strength) $=\frac{f_{c o}}{\rho_{s e y} E_{S} \varepsilon_{c o}}$

If $\kappa \leq 10, f_{h}=f_{h y}$

If $\kappa>10, f_{h}=0.43 \varepsilon_{c} E_{S}$

5. Where active confining pressures are present, this value is added to the passive to calculate the total confining stress ( $f^{\prime} h$ )

6. Determine the effective lateral confining stress in the concrete $\left(f_{l}^{\prime}=\rho_{\text {sey }} f_{h}\right)$

7. Compute the effective confinement index, $I^{\prime} e=\frac{f_{1}^{\prime}}{f_{c o}}$

8. Determine the compression strength of confined concrete, $f^{\prime}{ }_{c c}\left(=\left[1+2.4\left(I_{e}^{\prime}\right)^{0.7}\right] f_{c o}\right)$

9. Determine axial strain at peak compression strength, $\varepsilon_{c c}\left(=\left[1+35\left(I_{e}^{\prime}\right)^{1.2}\right] \varepsilon_{c o}\right)$

10. Calculate effective confinement index at $\varepsilon_{\mathrm{cc} 50},\left(I_{e}^{\prime}=\rho_{\text {sey }} \frac{f_{h y}}{f_{c o}}\right)\left(\varepsilon_{\mathrm{cc} 50} \sim 0.004\right.$, Cusson and Paultre, 1995) 
11. Plot the ascending and descending branches of $f_{c}$ using:

$$
\begin{aligned}
& \text { Ascending } f_{c}=f_{c c}^{\prime}=\left[\frac{k\left(\frac{\varepsilon_{c}}{\varepsilon_{c c}}\right)}{k-1+\left(\frac{\varepsilon_{c}}{\varepsilon_{c c}}\right)^{k}}\right], \varepsilon_{c} \leq \varepsilon_{c c} \\
& \text { Decending } f_{c}=f_{c c}^{\prime} \exp \left[k_{1}\left(\varepsilon_{c}-\varepsilon_{c c}\right)^{k_{2}}\right], \varepsilon_{c} \geq \varepsilon_{c c}
\end{aligned}
$$

From the above, it can be seen that the more a column is confined, the more likely it is to effectively utilise the yield strength of the transverse reinforcement.

Using the above relationships, the capacity of the three layouts analysed here to generate passive pressures have been calculated and are shown in Table 4. As may be seen, none of the configurations reach the unconditional yielding condition. It is noted that although the $56 \mathrm{~mm}$ spacing did not fully reach the unconditional yielding criteria and, while the yield strength of the transverse reinforcement is lower than that calculated, the unconditional yielding criterion was satisfied.

Once the passive pressures were established, the total confining pressures could be calculated, as shown in Table 5.

\subsection{Comparison of experimental and theoretical results}

\subsubsection{Test Series 2 (Passive)}

Table 6 shows the stress and strain comparison between the experimental results and predictions using the model above. It is clear from Table 6 that the full capacity of the confinement reinforcement was not utilised due to the initial misfit between the bands and the specimen. Figure 18 shows that the concrete dilated at an axial stress approximately $10 \mathrm{MPa}$ demonstrating that the confinement reinforcement was not sufficient to delay unstable propagation as the bands were not in full contact with the specimen allowing the concrete to behave in an unconfined nature.

It is clear that the behaviour of the post-peak region of the experimental stress-strain relationship is different to the unconfined specimen. While the confinement reinforcement did not increase the ultimate peak compressive stress of the specimen, it did have a 
significant effect on the observed ductility. As confinement stresses were not generated until the concrete cracked, the bands had enough capacity to generate confining forces after yielding leading to a decreased rate of strength degradation.

\subsubsection{Test Series 3}

The peak stresses in Test Series 3 are shown in Table 6. The results demonstrate an increase in stresses with a decrease in band spacing and increased volumetric ratio. The model also predicts a peak stress close to that measured and greater strength degradation than those predicted.

The predicted peak axial strains compare well with those measured with the exception of the $96 \mathrm{~mm}$ band spacing. However, this may be due to the performance of the gauge as beyond an axial stress of approximately $12 \mathrm{MPa}$, a distinct change occurs in readings leading to a stiffer pre-peak response. While the effect of initial active confinement on the concrete could be attributed to this, it has been concluded previously (Richart et al, 1929) that the response of concrete to active or passively generated confining pressures is the same.

\subsubsection{Test Series 4}

In Test Series 4, varying levels of pre-stress were investigated with a constant band spacing of $56 \mathrm{~mm}$. As a result, the spacing satisfies the unconditional yielding criterion and the maximum confining pressure that could be generated corresponds to the yield strength of the band. Therefore, the level of pre-stress applied will have no effect on the overall peak axial stress.

Table 6 shows similar peak stresses and strains respectively for the three levels of pre-stress. The low peak axial strain recorded for Level 3 may be due to the high initial confining pressure present before any cracking of the concrete occurred. As discussed previously, the stress-strain relationship for Level 1 indicated a decrease in stiffness at approximately $12 \mathrm{MPa}$ due to the performance of the gauge. 


\section{DISCUSSION OF RESULTS}

\subsection{Strength enhancement}

Table 3 presents the strength enhancements provided by the confinement in Test Series 3 and 4. As shown, there is a gradual increase in compressive strength as compared with the unconfined case (Test Series 1; 14.18MPa). However, it is clear that the different levels of prestress had no real effect on strength enhancement. For instance, with a band spacing of $56 \mathrm{~mm}$ and a prestress of 2.66MPa (Level 2), the same strength enhancement was achieved (1.53). However, the level of confinement stress on the concrete core had an effect on the confined concrete stress-strain behaviour of the cylinders. Specimens with greater lateral pressures at peak strength achieved significant strength enhancements with large axial strains.

The effects of creep on the pre-stress are considered to be minimal for static loading as found previously by Janke et al (2009). However, slightly higher ultimate axial deformations have been found in cyclic loading tests on confined FRP confinements on square and rectangular columns (Ilki et al, 2008). This behaviour was described as an effect of the longer duration of loading in cyclic tests which cause further deformations including creep effects.

While the strength enhancements are important, the column modulus should also be considered as it affects the stability when the column begins to micro crack at the point of confinement activation. This has been reported by De Lorenzis et al (2004) and Tamužs et al (2008).

\subsection{Ductility}

Plain concrete under uniaxial compression demonstrates brittle behaviour (spalling) and the deformability of concrete improves with confinement. Lateral support provided by transverse reinforcement is important to continue providing effective confinement against horizontal expansion so a stable reinforcement cage is essential. Therefore, the amount of transverse reinforcement, expressed in terms of the volumetric ratio $\left(\rho_{s}\right)$, plays a major role in the descending slope of the stress-strain relationship (Saatcioglu and Razvi, 1992). 
Here, an increase in ductility was observed for the confined specimens and large axial strains have been achieved with considerable peak strength enhancements.

Ilki et al (2008) found that the potential strength of vertical steel bars due to strain hardening could not be utilized until ultimate state was reached. Specimens with insufficient transverse reinforcement were found to fail with little confinement effects provided due to large spacing's. However, for closely spaced transverse bars, the behaviour was found to be more ductile. Rousakis and Karabinis (2012) focused on premature buckling of FRP confined columns supported by transverse steel subject to load-unload cyclic loading. The results found significant variations in the behaviour of confined FRP columns and is an area which warrants further research.

\subsection{Active and Passive confinement}

In instances where passive confinement techniques have been used higher levels of strength and ductility have been achieved. With close band spacing and high volumetric ratios of transverse reinforcement to the confined concrete core, the unconditional yielding criterion was achieved i.e., the band material yielded. Passive confining forces generated here were found to be approximately equally to the yield stress of the lateral reinforcement. In cases where the concrete is poorly confined, the lateral reinforcement can only generate reduced confining forces.

It is clear from the experimental work presented that passive confinement using steel bands is not effective as it is not activated prior to lateral strains (or dilation) taking place due to the initial misfit between the bands and the concrete. Because they are not in full contact with the cylinder, the concrete can dilate up to a point where it engages the transverse reinforcement. This confining point may be too late as the concrete could yield before the transverse reinforcement is activated. Confining forces are generated to contain the cracked specimens and the post peak behaviour is dictated by the remaining capacity of the confinement mechanism to generate confining forces.

It is clear from Test Series 3 that decreasing the spacing between the bands results in higher confining pressures and subsequent higher peak compressive stresses. The initial prestress applied to the bands ensured the element of misfit was eliminated and they were fully 
employed as a confining mechanism. The initial prestress applied to the $56 \mathrm{~mm}$ band spacing did not have an effect here as it satisfied the unconditional yielding criterion where the bands yielded before the concrete failed. However, the initial prestress in the 150 and $96 \mathrm{~mm}$ spacing's did contribute to an increase in the compressive strength as the concrete could only generate minor band stresses due to the large spacing's and small volumetric ratios. The addition of the initial prestress resulted in higher confining pressures being generated than would have been otherwise achieved through passive confinement alone.

Results from Test Series 4 indicate that the prestress did increase the load-carrying capacity, on average, by $53 \%$. This was achieved because the bands were fully activated and yielding occurred at peak compressive stress.

If Test Series 4 were conducted with low confinement ratios and high tensile strength straps, the initial levels of prestress would have a greater effect on the strength enhancement and better conclusions could be drawn regarding the optimum levels of pre-stress applied prior to loading. Once the passive pressure generation limit is achieved, the addition of the active forces will yield an increase in the peak compressive stress.

\section{CONCLUSIONS}

A summary of the conclusions are below:

- Confining the concrete did produce an increase in compressive strength but differing levels of pre-stress had no significant effect on strength enhancement. However, the level of pre-stress did effect the confined concrete stress-strain behaviour with greater lateral stresses at peak strength observed obvious strength enhancements.

- Unconfined and un-pre-stressed plain concrete exhibited brittle behaviour improving with the addition of confinement. Following peak stress, the amount of transverse reinforcement, expressed in terms of the volumetric ratio $\left(\rho_{s}\right)$, plays a major role in the stress-strain behaviour.

- Ductility increases were observed for confined specimens and significant axial strains achieved with noticeable peak strength enhancements. Passive confinement has also 
shown improvements in strength and ductility. Passive confining and yield stresses of the lateral reinforcement were found to be equal.

- Misfit between the bands and concrete leads to ineffective confinement as it is only activated when the concrete dilates under loading. As a result, confining forces generated only contain the cracked specimens. The post peak behaviour dictated by the remaining capacity of the band to generate confining forces.

- Decreasing the band spacing leads to higher confining pressures and peak compressive stresses. By initially pre-stressing the bands, higher confining pressures were generated than would have possible using passive confinement alone and an increase in load capacity of 53\% was observed as the bands were fully activated. 


\section{REFERENCES}

ASTM C39, Standard Test Method for Compressive Strength of Cylindrical Concrete Specimens, 2004

BS EN 12350-2, Testing fresh concrete. Slump-test, 2009

De Lorenzis L., Tamužs V., Tepfers R., Valdmanis V. and Vilks U. (2004) Stability of CFRP-confined columns. Innovative Materials and Technologies for Construction and Restoration Conference, Lecce, pp. 327-342.

EN 197-1, Cement: Composition, Specifications and Conformity Criteria for Common Cements, British Standards Institution, London, 2000

Fardis, M.N (2009), Seismic design, assessment and retrofitting of concrete buildings based on EN-Eurocode 8, Springer

Frangou, M., Pilakoutas, K. \& Dritsos, S. (1995). Structural repair/strengthening of RC columns, Construction and Building Materials journal, Vol. 9, No. 5, pp259-266

Ilki, A., Peker, O., Karamuk, E., Demir, C. and Kumbasar, N. (2008). FRP Retrofit of Low and Medium Strength Circular and Rectangular Reinforced Concrete Columns, Journal of Materials in Civil Engineering, (20), pp. 169-188.

Iyengar, K.T., Desayi, P. \& Reddy, K.N. (1970). Stress-strain characteristics of concrete confined in steel binders, Magazine of Concrete Research, Vol. 22, No. 72, pp. 173-184

Janke L., Czaderski C., Ruth J., Motavalli M. Experiments on the residual load-bearing capacity of prestressed confined concrete columns. Engineering Structures, Volume 31, Issue 10, October 2009, Pages 2247-2256 (2009).

Legeron, F. \& Paultre, P. (2003). Uniaxial confinement model for normal and high strength concrete columns, ASCE Journal of Structural Engineering, Vol. 129, No. 241-252 
Mirmiran, A. \& Shahawy, M. (1997). Dilation characteristics of confined concrete, Mechanics of Cohesive-Frictional Materials, Vol. 2, pp. 237-249

Moghaddam H., Samadi M., Pilakoutas K., Mohebbi S. (2010a) Axial compressive behavior of concrete actively confined by metal strips; part A: experimental study. Materials and Structures, Vol, 43, pp. 1369-1381.

Moghaddam H., Samadi M., Pilakoutas K. (2010b) Compressive behavior of concrete actively confined by metal strips, part B: analysis, Materials and Structures, Vol. 43, pp. 1383-1396.

Rodriguez, M. \& Park, R. (1994). Seismic load tests of reinforced concrete columns strengthened by jacketing. Structural Journal of American Concrete Institute, 91: 150-159

Rousakis T.C., Karabinis A.I. (2012). Adequately FRP confined reinforced concrete columns under axial compressive monotonic or cyclic loading. RILEM Materials and Structures, Springer Netherlands, 2012;45(7) 957-975

Rousakis, T. (2013): Hybrid Confinement of Concrete by FRP Sheets and Fiber Ropes Under Cyclic Axial Compressive Loading. ASCE Journal of Composites for Construction, 17(5), 732-743.

Rousakis, T. (2014): Elastic Fiber Ropes of Ultrahigh-Extension Capacity in Strengthening of Concrete Through Confinement. ASCE Journal of Materials in Civil Engineering, 26(1), 3444.

Rousakis T.C. and Tourtouras I.S. (2014): RC Columns of Square Section - Passive and Active Confinement with Composite Ropes. Elsevier, Journal of Composites Part B: Engineering. Volume 58, March 2014, pages 573-581.

Saatcioglu, M, \& Razvi, S.R. (1992). Strength and Ductility of Confined Concrete”, ASCE Journal of Structural Engineering, Vol.118, No.6, pp. 1590-1607 
Sheikh, S.A.; and Toklucu, M.T. (1993) Reinforced Concrete Columns Confined by Circular Spirals and Hoops, ACI Structural Journal, Vol.90 (5), pp.542-553.

Shin, M. and Andrawes, B. (2010). Experimental investigation of actively confined concrete using shape memory alloys, Engineering Structures, Vol. 32 (3), pp. 656-664

Tamuzs V., Tepfers R., Chi-Sang You, Rousakis T., Repelis I., Skruls V. and Vilks U (2006) Behaviour of Concrete Cylinders Confined by Carbon-Composite Tapes and Prestressed Yarns 1 - Experimental data. Mechanics of Composite Materials. Vol 42, No 1, pp. 13-32.

Tamužs V., Tepfers R., Zīle E. and Valdmanis V (2008). Mechanical behaviour of FRPconfined concrete columns under axial compressive loading. American Society of Civil Engineers, International Committee, Los Angeles Section, 5th International Engineering and Construction Conference (IECC’5), pp. 223-241.

Tepfers R., (2012) Concerning Concrete E-Modulus. Riga Technical University 53rd International Scientific Conference dedicated to the 150th anniversary and The 1st Congress of World Engineers and Riga Polytechnic Institute / RTU Alumni. DIGEST. ISBN 978-993410-360-5, pp 360-361.

Valdmanis V., De Lorenzis L., Rousakis T. and Tepfers R (2007) Behaviour and Capacity of CFRP-Confined Concrete Cylinders Subjected to Monotonic and Cyclic Axial Compressive Load. Structural Concrete, Vol 8, No. 7.

Yan Z., Pantelides C.P., Reaveley L.D. Posttensioned FRP Composite Shells for Concrete Confinement. ASCE Journal of Composites for Construction, Vol. 11, No. 1, February 1, (2007), pp.81-90.

Xiao, Y., Wu, H. (2003). Retrofit of reinforced concrete columns using partially stiffened steel jackets, ASCE Journal of Structural Engineering, Vol. 129, No. 6, pp. 725-732 


\section{LIST OF FIGURES}

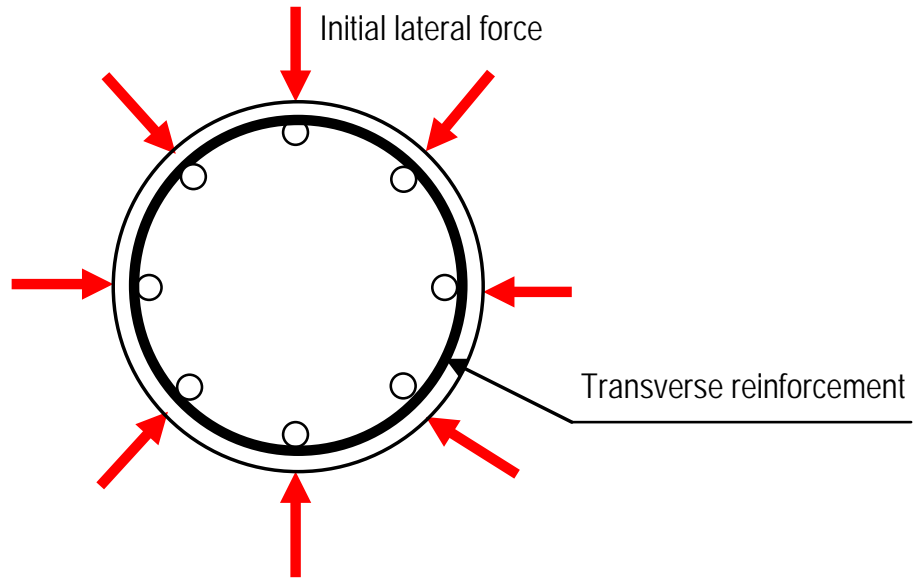

Figure 1 Active transverse reinforcement

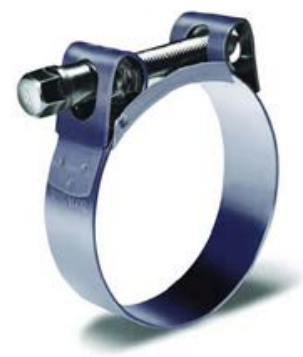

Figure 2 Mild steel band clamp used to apply the prestress. 

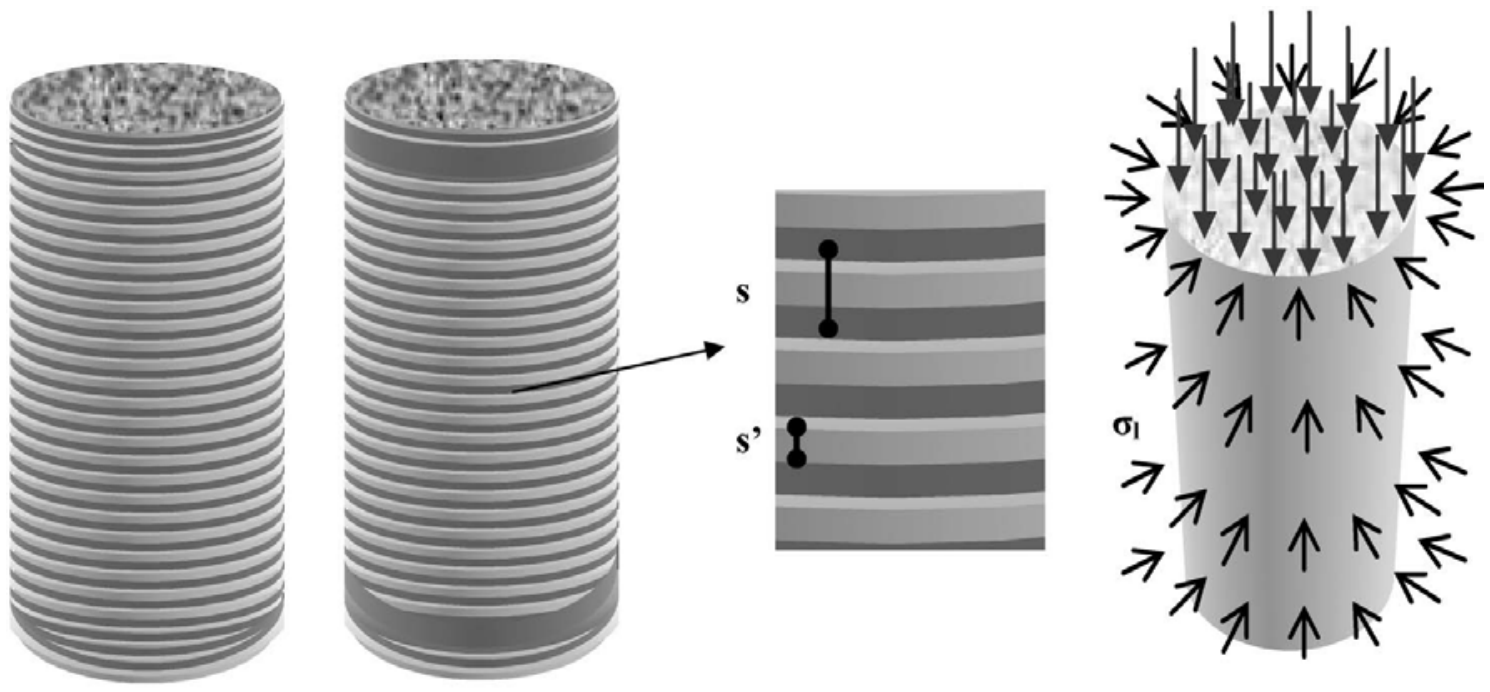

Figure 3 Layout of FR confinement and stress state (Rousakis, 2014)
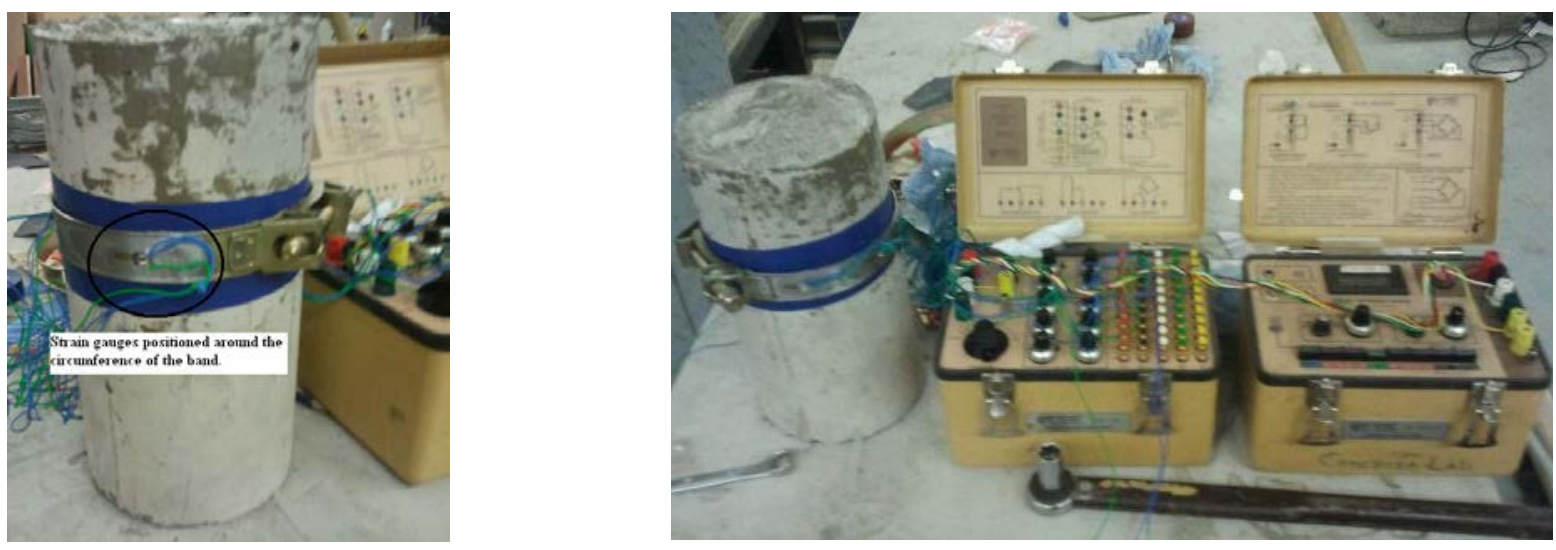

Figure $4 \quad$ Material tests setup

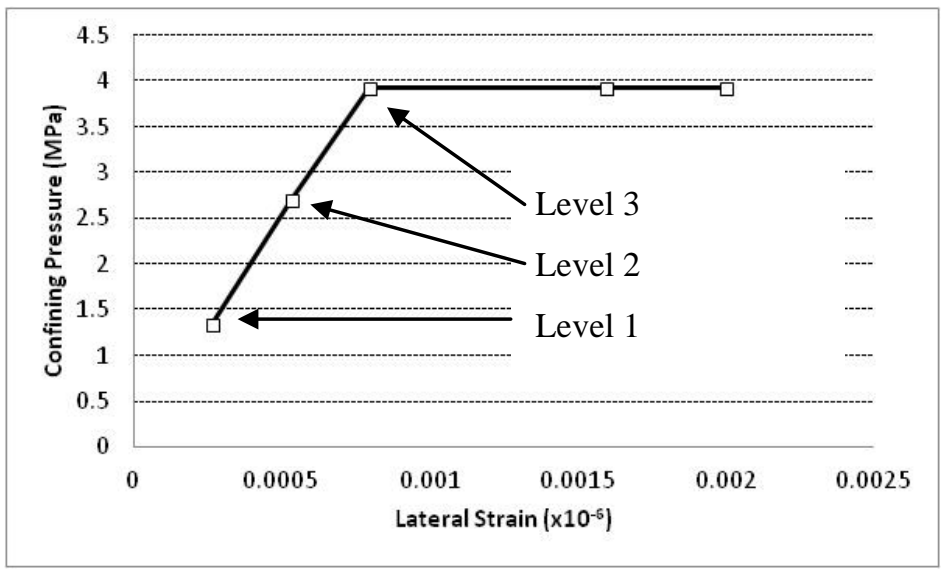

Figure 5 Corresponding confining pressure with lateral strain 


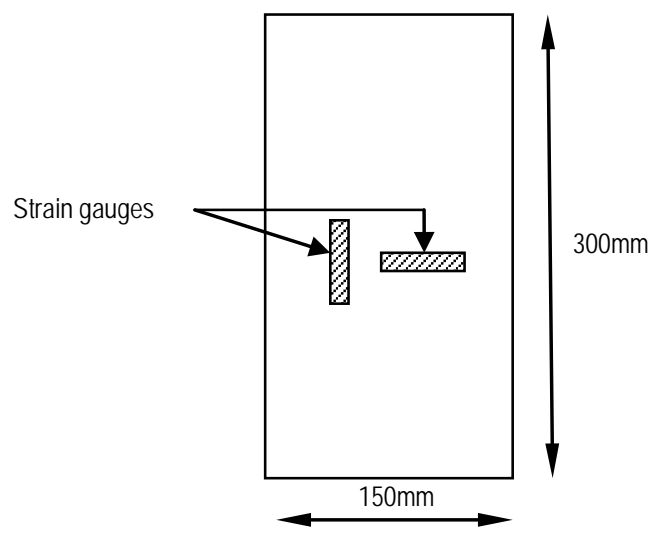

Figure $6 \quad$ Sample set-up for Test Series 1
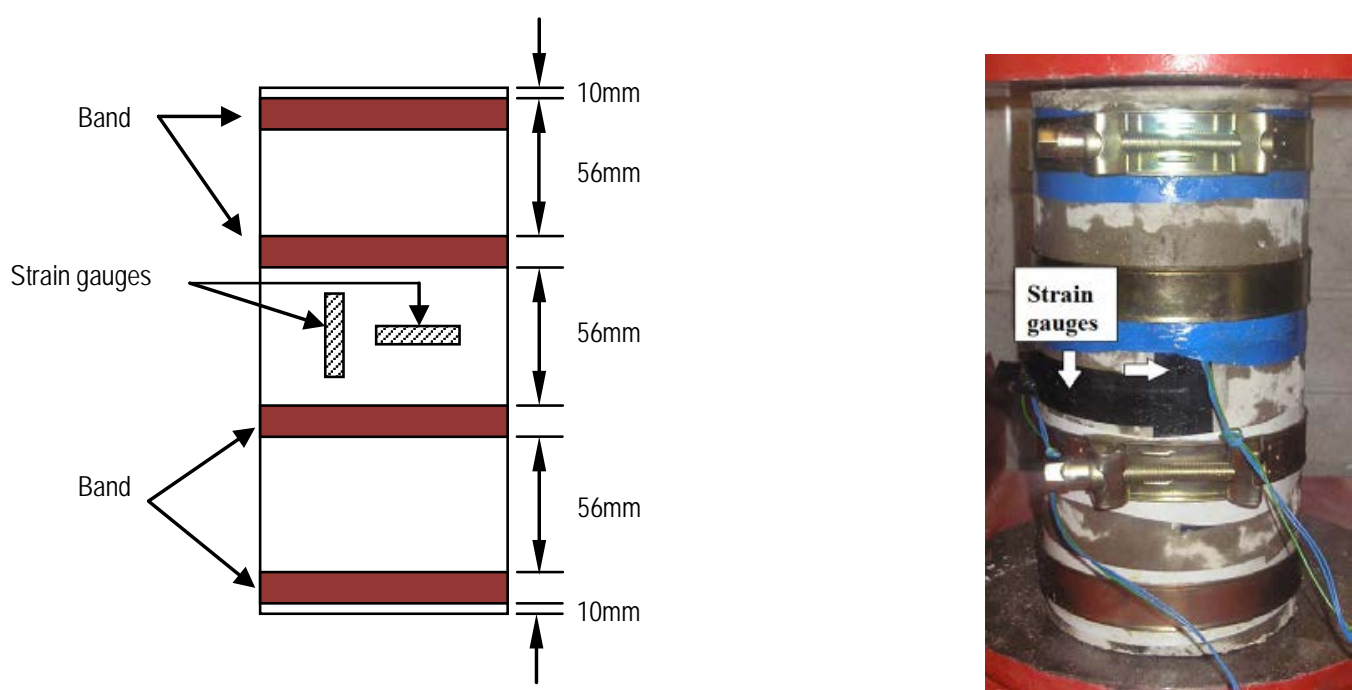

Figure $7 \quad$ Sample set-ups for Test Series 2 

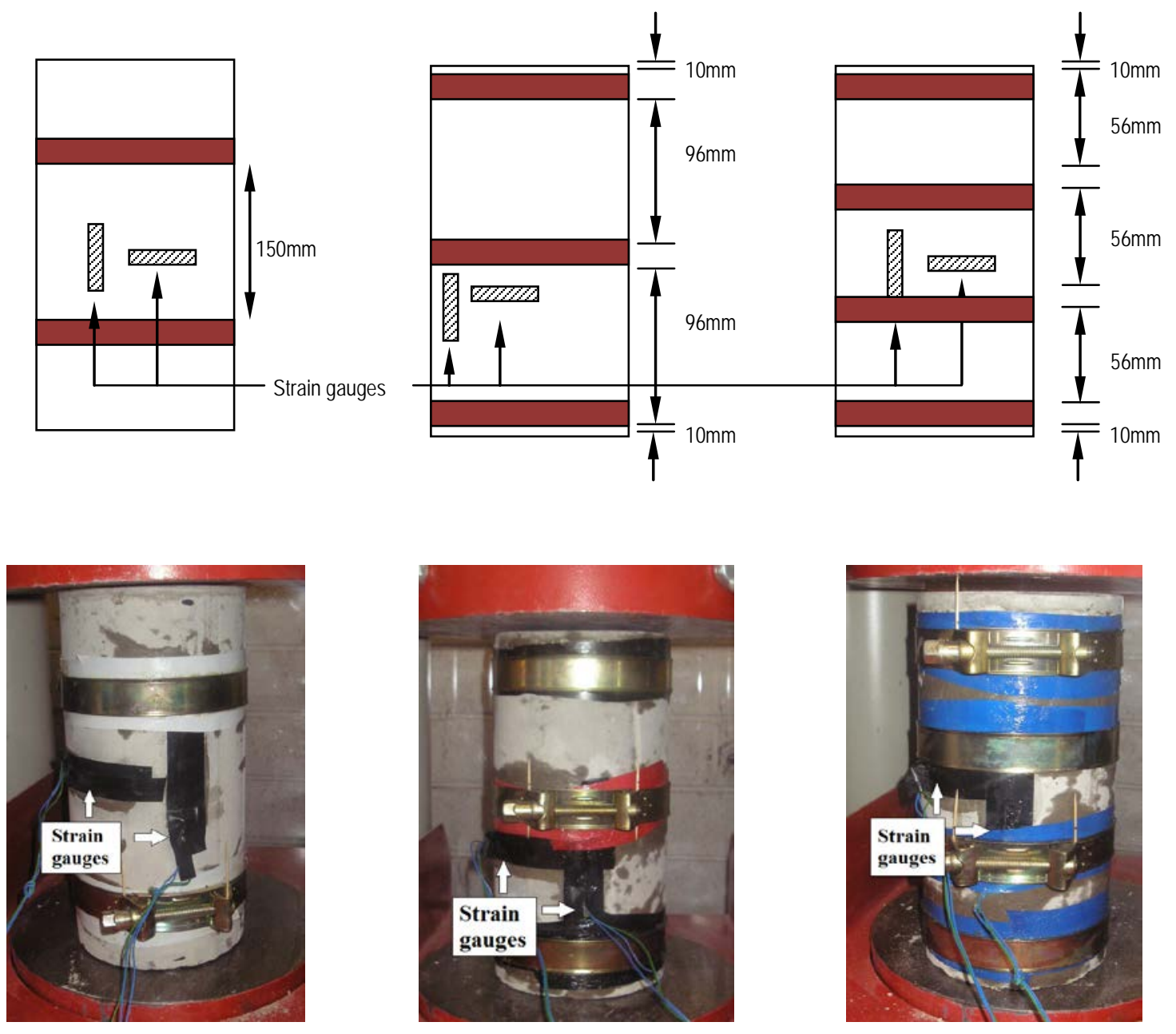

Figure $8 \quad$ Sample set-ups for Test Series 3 

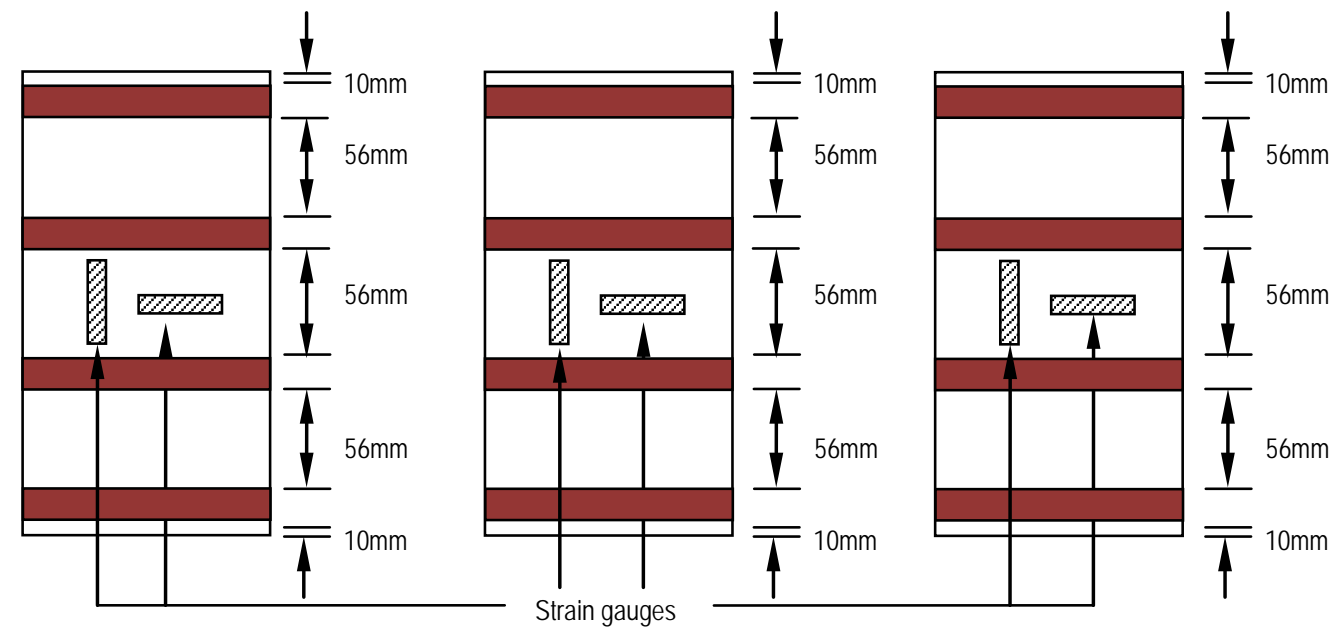

(a)1.34MPa

(b) $2.66 \mathrm{MPa}$

(c) $3.93 \mathrm{MPa}$

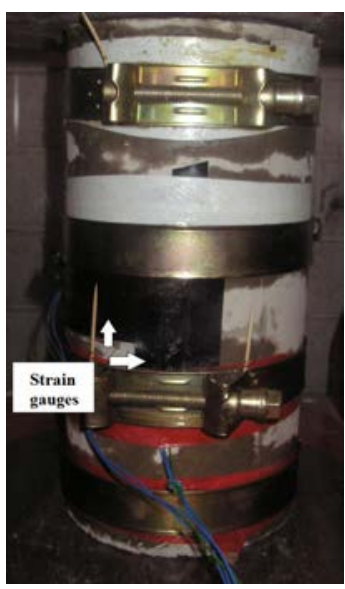

(a)

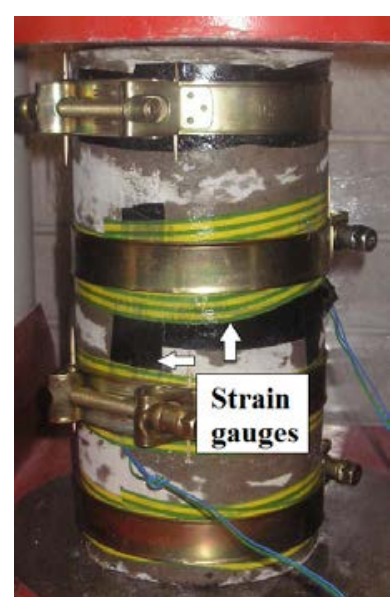

(b)

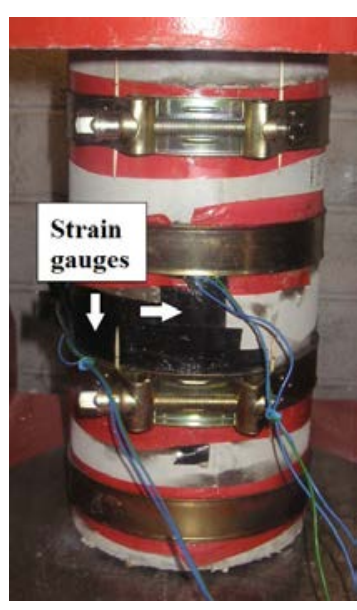

(c)

Figure $9 \quad$ Sample set-ups for Test Series 4 


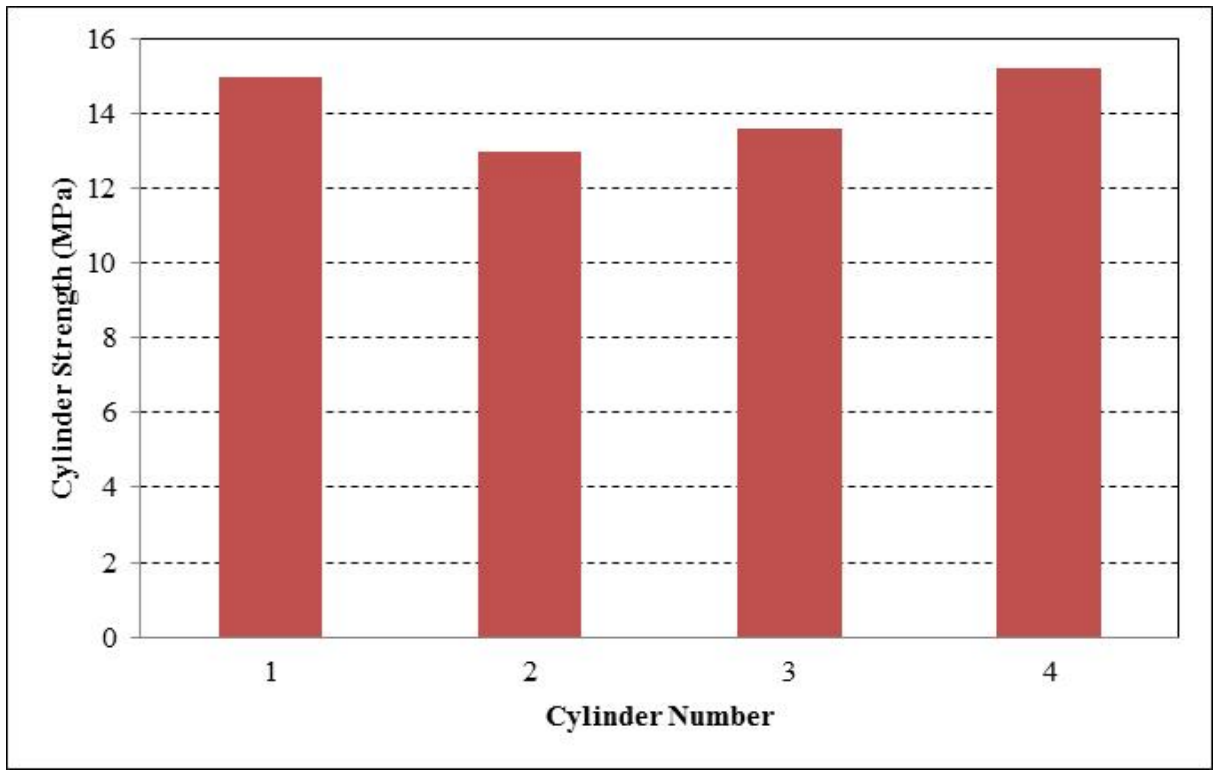

Figure 10 Unconfined compressive strengths from Test Series 1
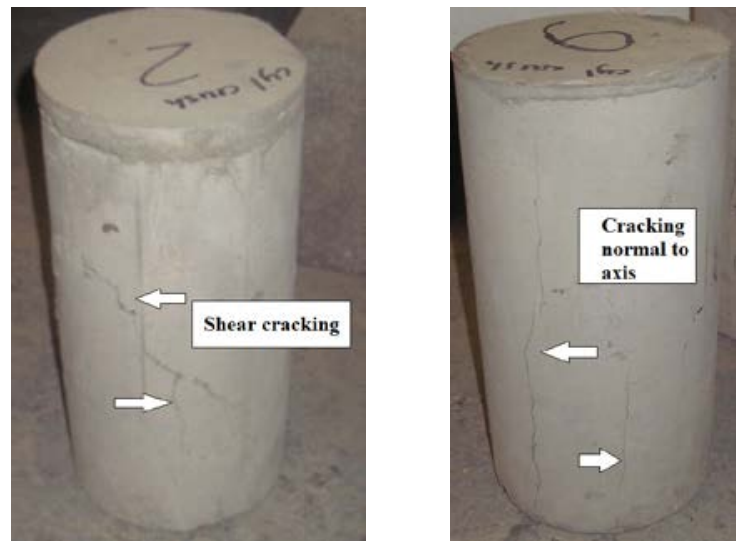

Figure 11 Failure modes of unconfined concrete 


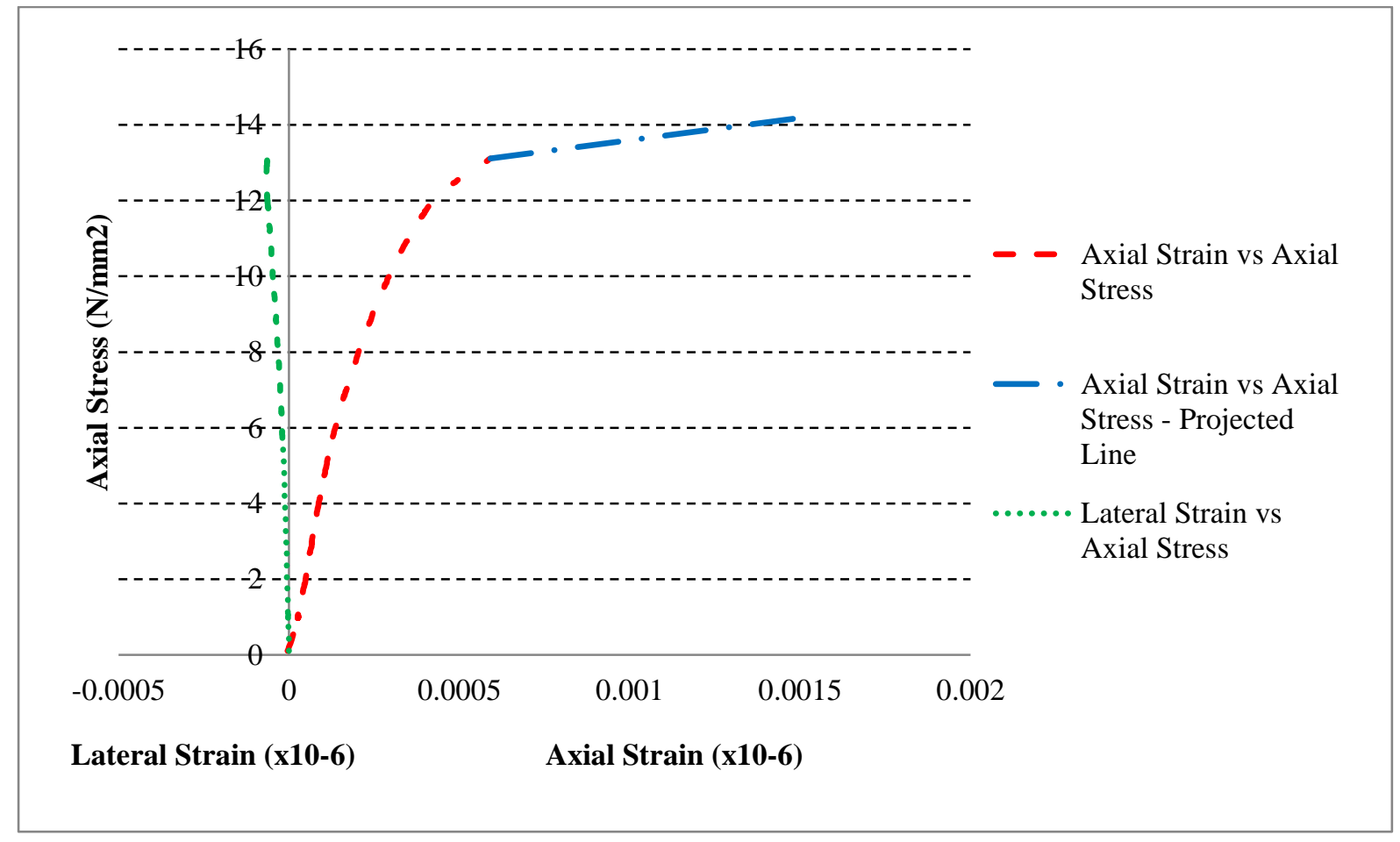

Figure 12 Stress-strain curves for Test Series 1

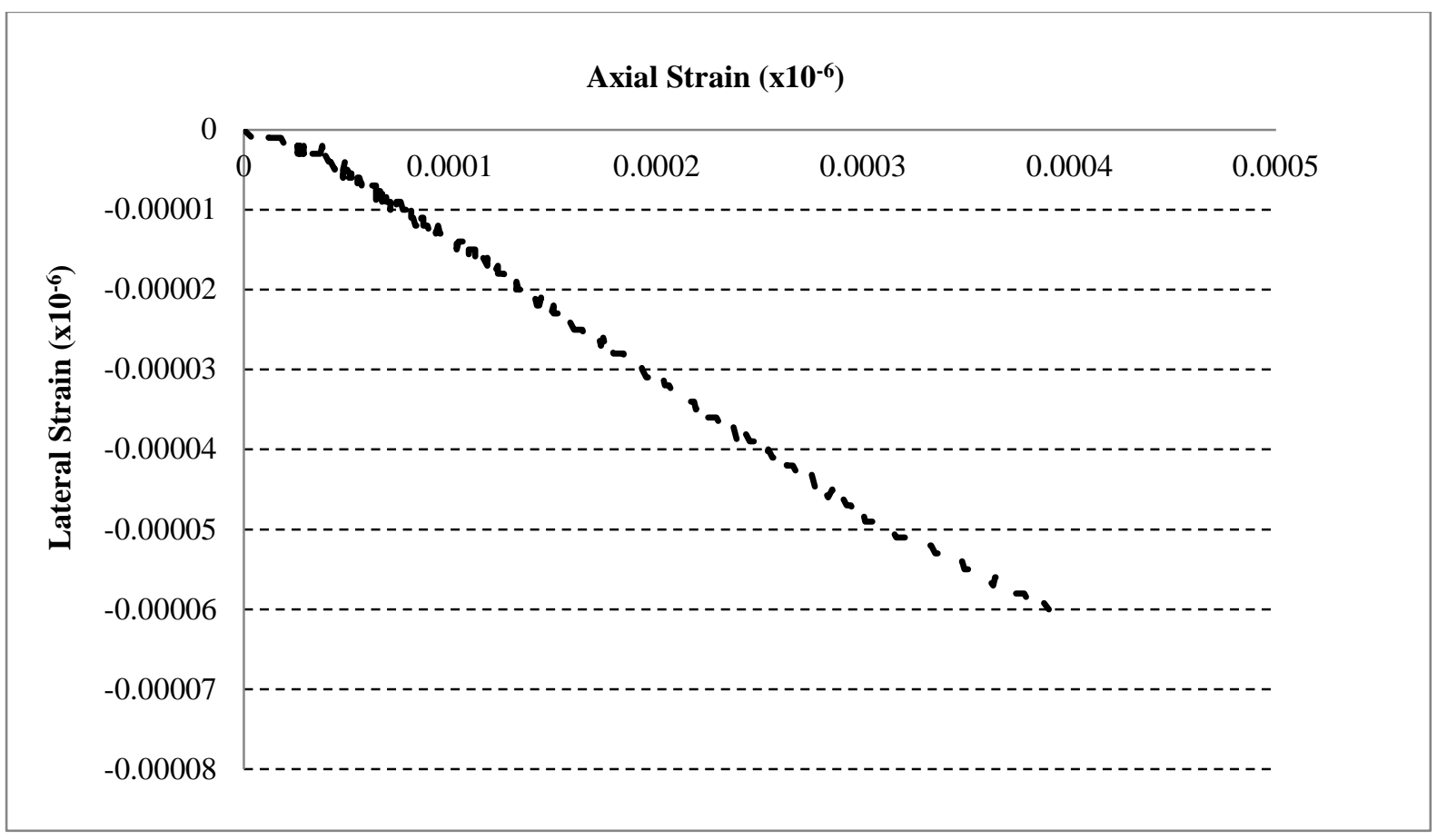

Figure 13 Determination of Poisson's ratio for Test Series 1 


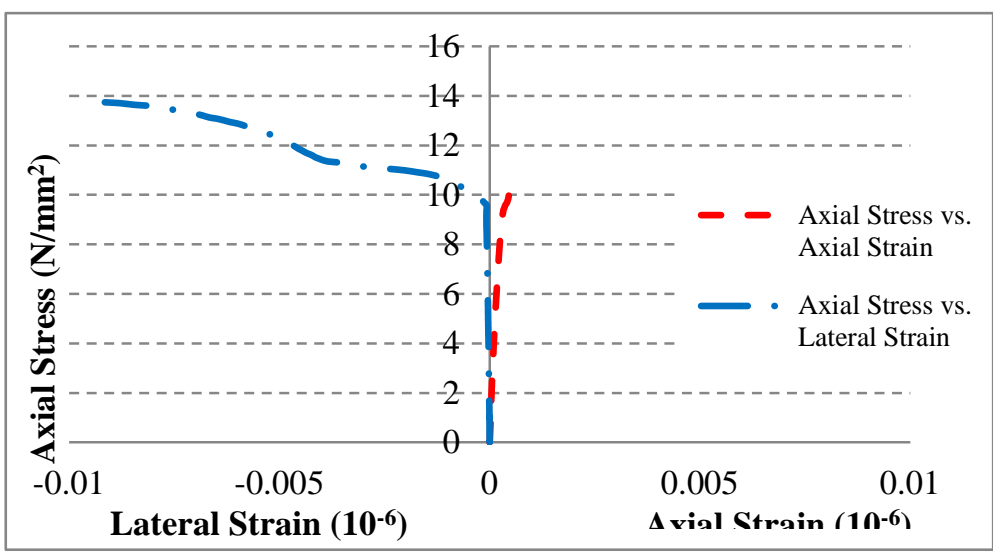

(a)

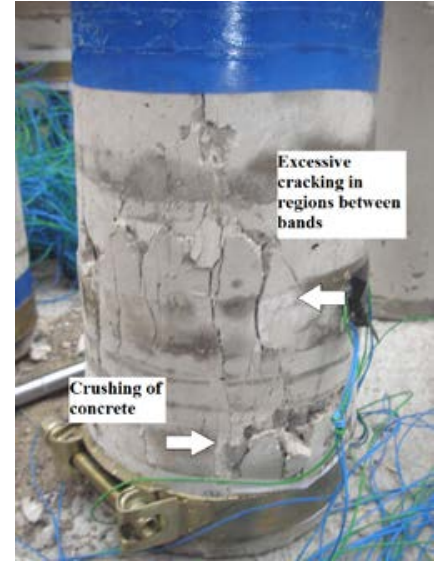

(b)

Figure 14 (a) Stress-strain graph for Test Series 2 and (b) cracking observed

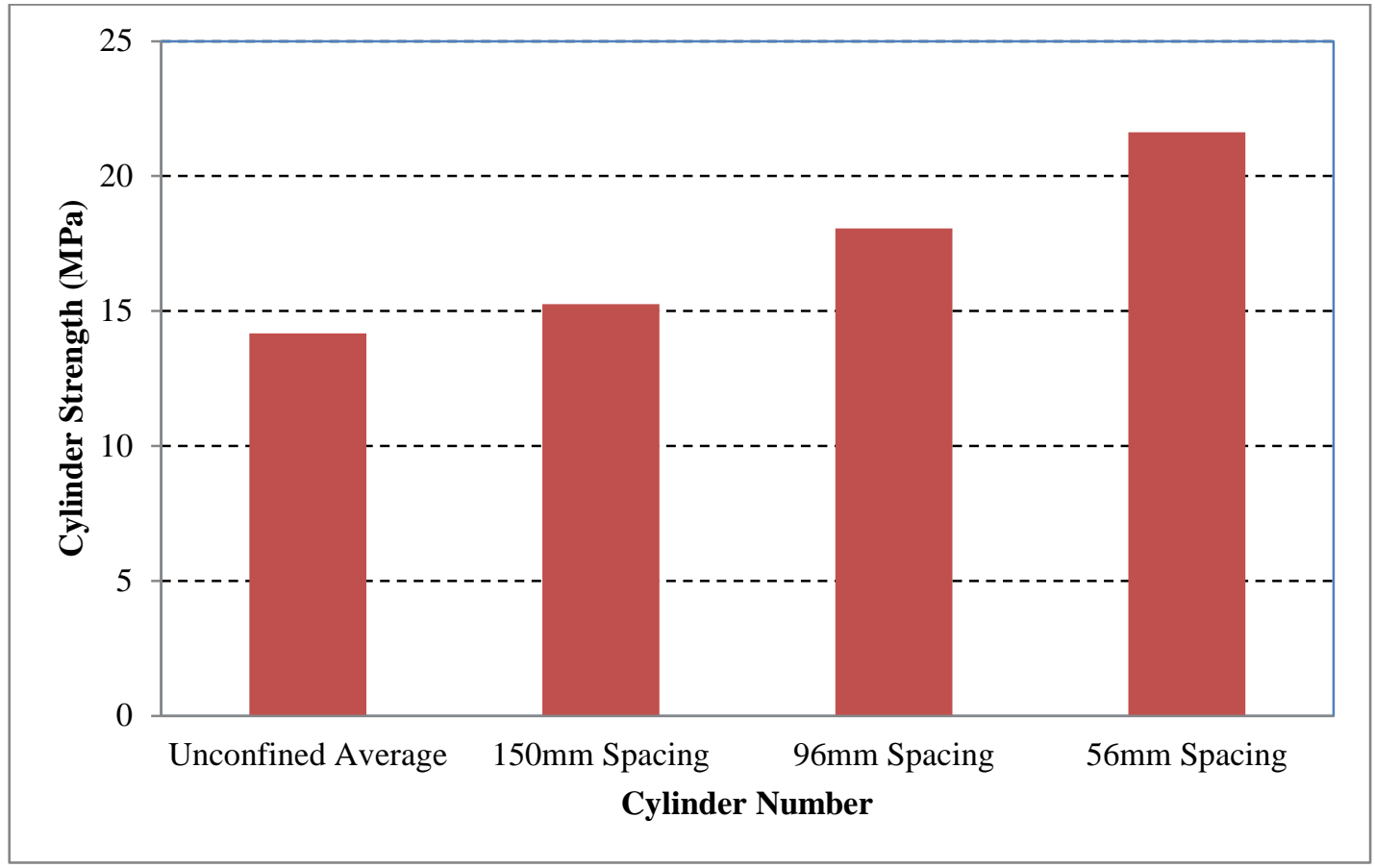

Figure $15 \quad$ Test Series 3 compressive load results 


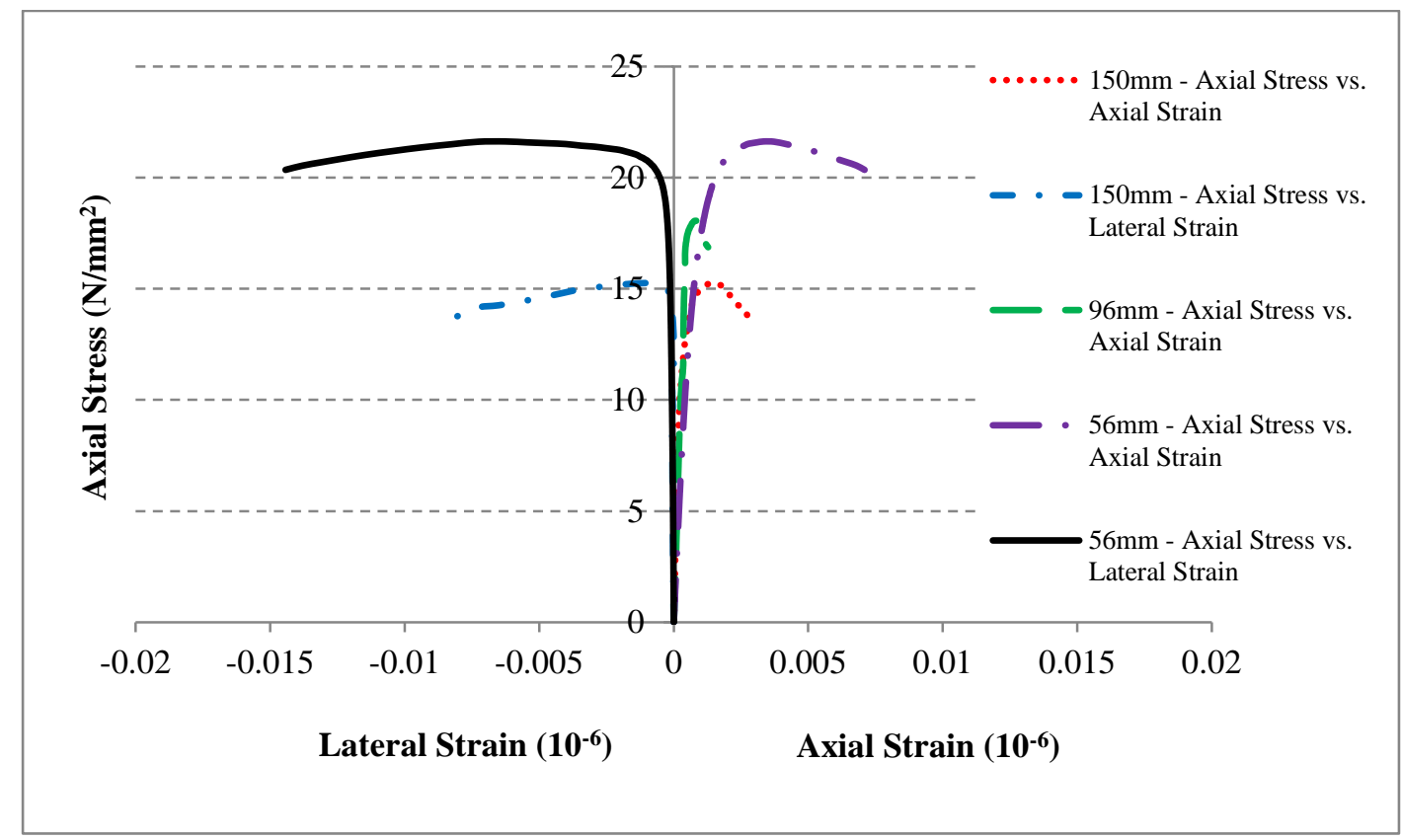

Figure $16 \quad$ Test Series 3 - varying spacing stress-strain results
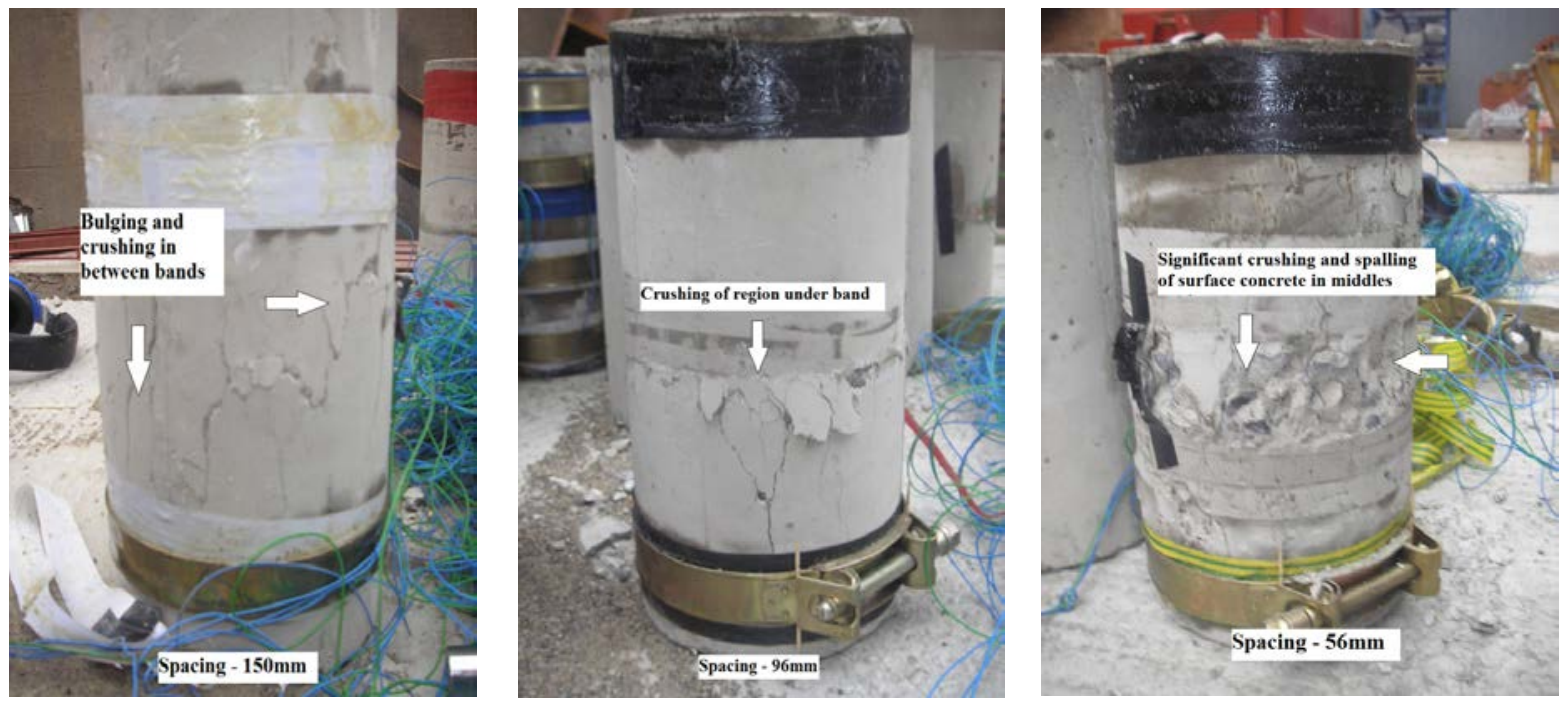

Figure 17 Test Series 3 modes of failure 


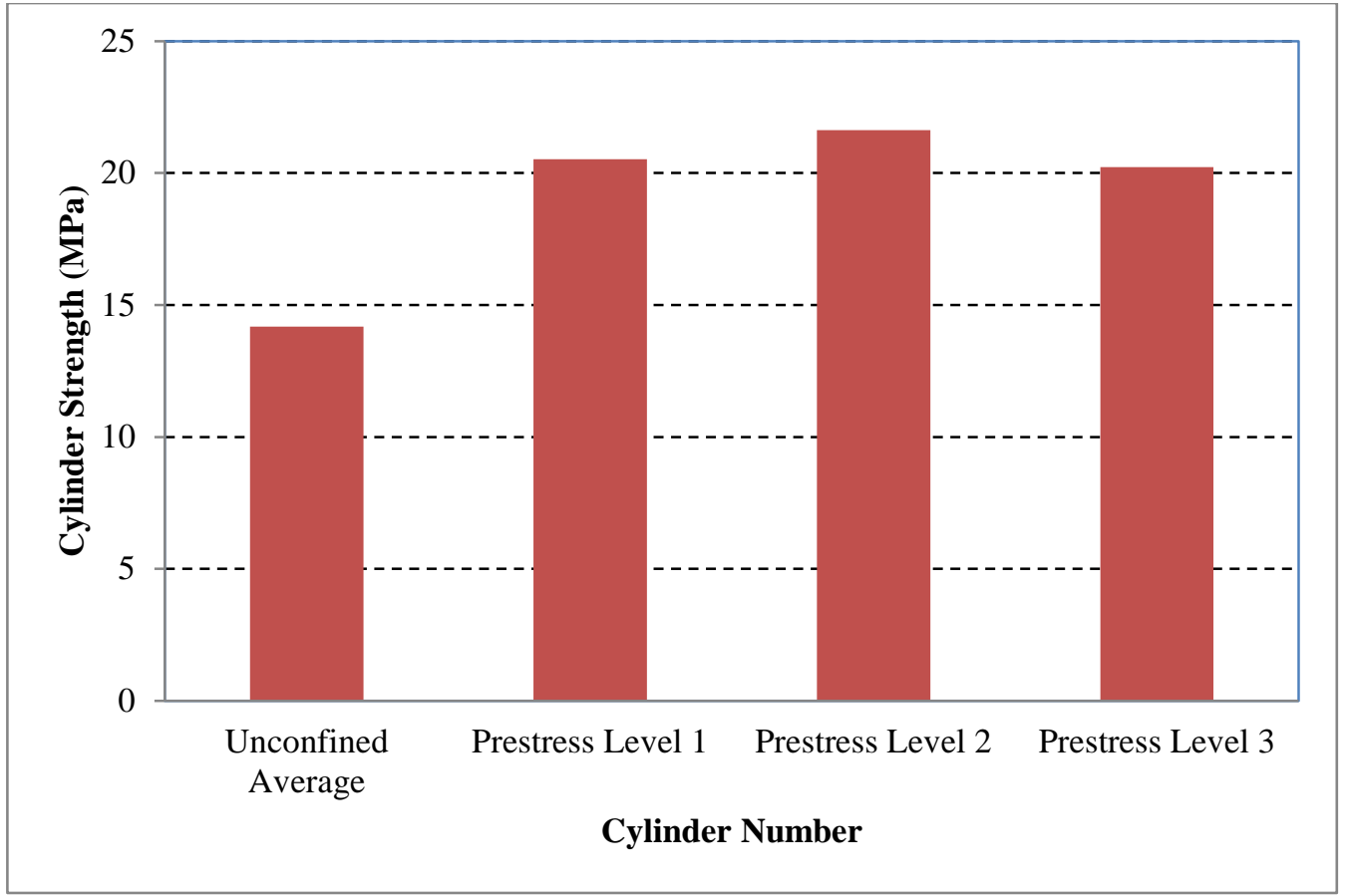

Figure 18 Test Series 4 compressive load results

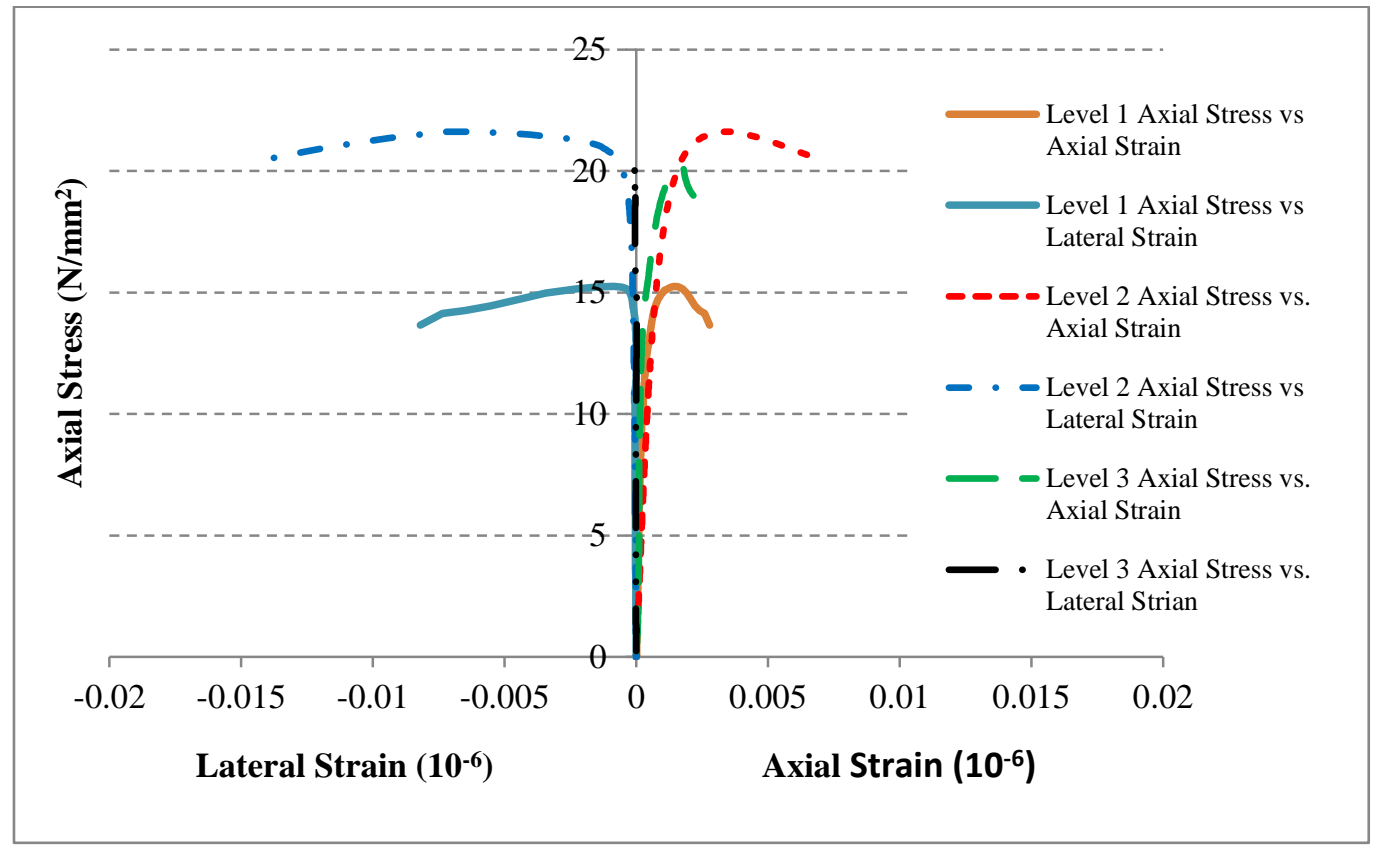

Figure 19 Test Series 4 Stress-strain graphs with constant band spacing and varying prestress. 

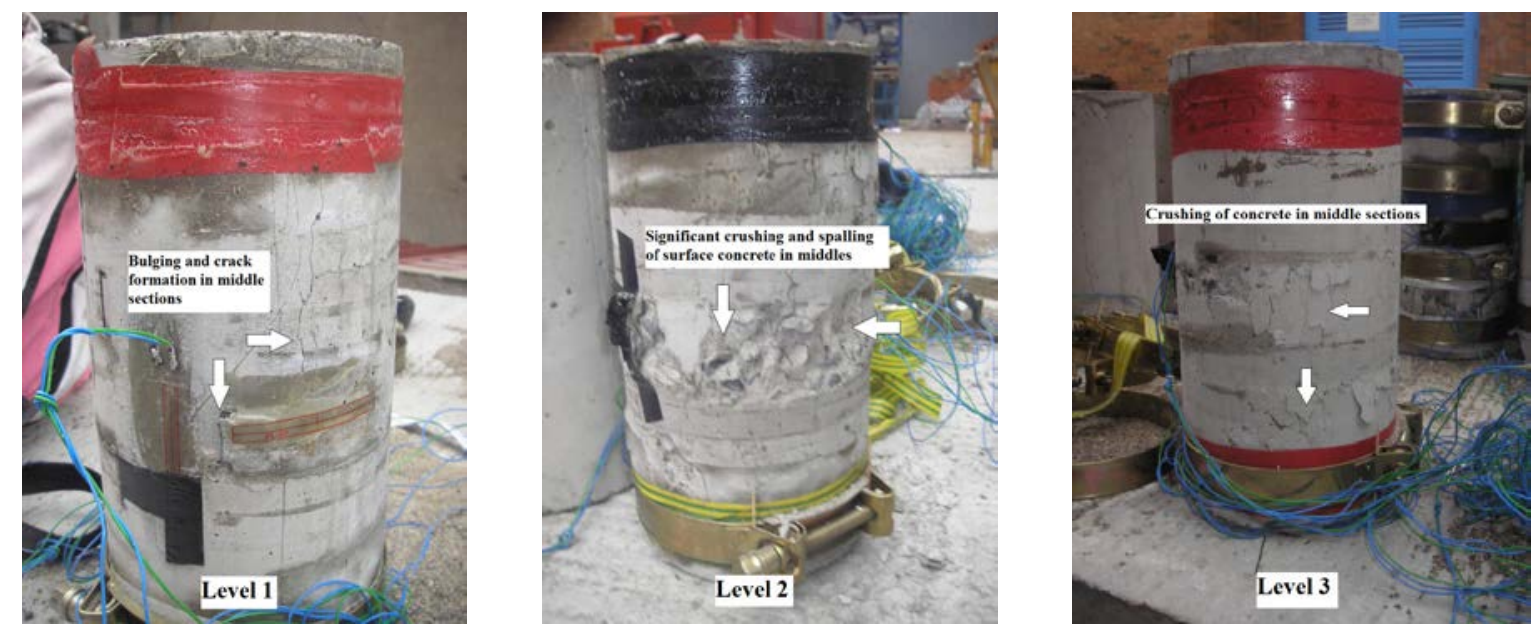

Figure 20 Test Series 4 cracked specimens. 


\section{LIST OF TABLES}

Table $1 \quad$ Mix proportions

\begin{tabular}{|c|c|c|c|c|c|c|}
\hline $\mathbf{a} / \mathbf{b}$ & FA/CA & $\begin{array}{c}\text { Water } \\
\mathbf{k g} / \mathbf{m}^{\mathbf{3}}\end{array}$ & $\begin{array}{c}\text { CEM I } \\
\mathbf{k g} / \mathbf{m}^{\mathbf{3}}\end{array}$ & $\begin{array}{c}\text { FA } \\
\mathbf{~ k g} / \mathbf{m}^{\mathbf{3}}\end{array}$ & \multicolumn{2}{|c|}{$\begin{array}{c}\text { CA } \\
\mathbf{k g} / \mathbf{m}^{\mathbf{3}}\end{array}$} \\
\hline 4.03 & 0.89 & 205 & 436 & 827 & $10 \mathrm{~mm}$ & $20 \mathrm{~mm}$ \\
\cline { 5 - 7 } & & & & 317 & 615 \\
\hline
\end{tabular}

FA - Fine aggregate

CA - Course Aggregate

$\mathrm{a} / \mathrm{b}$ - aggregate-binder ratio

Table 2 Relationship between gap width, hoop stress and confining pressure.

\begin{tabular}{|c|c|c|c|}
\hline & $\begin{array}{c}\text { Gap width } \\
\left(\boldsymbol{\delta}_{\mathbf{H}}, \mathbf{m m}\right)\end{array}$ & $\begin{array}{c}\text { Hoop Stress } \\
\mathbf{( M P a )}\end{array}$ & $\begin{array}{c}\text { Confining Pressure } \\
\mathbf{( M P a )}\end{array}$ \\
\hline Specimen 1 & 0.1 & 60.84 & 1.34 \\
\hline Specimen 2 & 0.2 & 121.6 & 2.66 \\
\hline Specimen 3 & 0.3 & 177.17 & 3.93 \\
\hline
\end{tabular}

Table 3 Strength enhancement in Test Series 3 \& 4 compared to the unconfined average.

\begin{tabular}{|c|c|c|c|c|}
\hline $\begin{array}{c}\text { Test } \\
\text { Series }\end{array}$ & $\begin{array}{c}\text { Band } \\
\text { Spacing } \\
\mathbf{( m m )}\end{array}$ & $\begin{array}{c}\text { Prestress } \\
\text { Level } \\
\text { (Figure 9) }\end{array}$ & $\begin{array}{c}\text { Compression } \\
\text { strength } \\
\mathbf{( M P a )}\end{array}$ & $\begin{array}{c}\text { Strength } \\
\text { Enhancement }\end{array}$ \\
\hline \multirow{2}{*}{3} & 150 & \multirow{2}{*}{2} & 15.25 & 1.08 \\
\cline { 2 - 3 } \cline { 4 - 5 } & 96 & 18.06 & 1.27 \\
\cline { 2 - 3 } & 56 & 1 & 21.63 & 1.53 \\
\hline \multirow{2}{*}{4} & \multirow{2}{*}{56} & 2 & 21.63 & 1.45 \\
\cline { 5 - 5 } & & 3 & 20.22 & 1.43 \\
\hline
\end{tabular}


Table 4 Passive confining stress capacities

\begin{tabular}{|l|l|l|l|l|l|l|l|l|}
\hline $\begin{array}{l}f_{c o} \\
(\mathbf{M P a})\end{array}$ & $\varepsilon_{c o}$ & $\begin{array}{l}\boldsymbol{E}_{\boldsymbol{s}} \\
\mathbf{( M P a )}\end{array}$ & $\begin{array}{l}\boldsymbol{s} \\
\mathbf{( m m )}\end{array}$ & $\boldsymbol{k e}$ & $\boldsymbol{\rho}_{\text {sey }}$ & $\boldsymbol{k}$ & Criteria & $\begin{array}{l}\boldsymbol{f}^{\prime} \boldsymbol{} \\
\mathbf{( M P a})\end{array}$ \\
\hline 14.2 & 0.00143 & 19300 & 56 & 0.6615 & 0 & 10.32 & Not yielded & 739.74 \\
\hline 14.2 & 0.00143 & 19300 & 96 & 0.4624 & 0 & 21.80 & Not yielded & 29.47 \\
\hline 14.2 & 0.00143 & 19300 & 150 & 0.25 & 0 & 57.89 & Not yielded & 10.43 \\
\hline
\end{tabular}

Table $5 \quad$ Confining Stresses

\begin{tabular}{|c|c|c|c|c|}
\hline & \multicolumn{2}{|c|}{$\begin{array}{c}\text { Active Stress } \\
\text { (MPa) }\end{array}$} & $\begin{array}{c}\text { Passive } \\
\text { Stress (MPa) }\end{array}$ & $\begin{array}{l}\text { Total } \\
\text { (MPa) }\end{array}$ \\
\hline$\stackrel{\sim}{\mathscr{E}}$ & \multicolumn{2}{|c|}{0} & 117.17 & 117.17 \\
\hline \multirow{4}{*}{ 总 } & $\begin{array}{l}\text { Spacing } \\
\text { (mm) }\end{array}$ & $\begin{array}{c}\text { Active Stress } \\
\text { (MPa) }\end{array}$ & $\begin{array}{c}\text { Passive } \\
\text { Stress (MPa) }\end{array}$ & $\begin{array}{l}\text { Total } \\
\text { (MPa) }\end{array}$ \\
\hline & 56 & 120.5 & 56.67 & 177.17 \\
\hline & 96 & 120.5 & 29.47 & 149.97 \\
\hline & 150 & 120.5 & 10.43 & 130.93 \\
\hline \multirow{4}{*}{ • } & $\begin{array}{c}\text { Pre-stress } \\
\text { Level }\end{array}$ & $\begin{array}{c}\text { Active Stress } \\
\text { (MPa) }\end{array}$ & $\begin{array}{c}\text { Passive } \\
\text { Stress (MPa) }\end{array}$ & $\begin{array}{l}\text { Total } \\
\text { (MPa) }\end{array}$ \\
\hline & 1 & 60.5 & 116.67 & 177.17 \\
\hline & 2 & 120.5 & 56.67 & 177.17 \\
\hline & 3 & 117.17 & 0 & 177.17 \\
\hline
\end{tabular}


Table $6 \quad$ Experimental and predicted Peak stress comparisons

\begin{tabular}{|c|c|c|c|c|c|}
\hline & & $\begin{array}{c}\text { Experimental } \\
\text { Peak Stress } \\
\text { (MPa) }\end{array}$ & $\begin{array}{c}\text { Experimental } \\
\text { Peak Strain } \\
\left(\mathrm{x} 10^{-6}\right)\end{array}$ & $\begin{array}{c}\text { Predicted } \\
\text { peak } \\
\text { Stress } \\
\text { (MPa) }\end{array}$ & $\begin{array}{c}\text { Predicted } \\
\text { peak } \\
\text { Strain } \\
\left(\times 10^{-6}\right)\end{array}$ \\
\hline \multirow{2}{*}{ 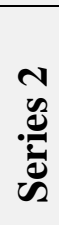 } & $\begin{array}{c}\text { Unconfined } \\
\text { Average }\end{array}$ & 14.18 & 1430 & 14.18 & 1430 \\
\hline & Passive & 14.03 & NA & 20.16 & 3070 \\
\hline \multirow{4}{*}{ • } & $\begin{array}{c}\text { Unconfined } \\
\text { Average }\end{array}$ & 14.18 & 1430 & 14.18 & 1430 \\
\hline & $\begin{array}{l}56 \mathrm{~mm} \\
\text { spacing }\end{array}$ & 21.63 & 3340 & 20.16 & 3070 \\
\hline & $\begin{array}{c}\text { 96mm } \\
\text { spacing }\end{array}$ & 18.06 & 1945 & 17.75 & 2005 \\
\hline & $\begin{array}{l}\text { 150mm } \\
\text { spacing }\end{array}$ & 15.25 & 1431 & 15.38 & 1587 \\
\hline \multirow{4}{*}{ • } & $\begin{array}{c}\text { Unconfined } \\
\text { Average }\end{array}$ & 14.18 & 1430 & 14.18 & 1430 \\
\hline & $\begin{array}{c}\text { Level } 1 \text { Pre- } \\
\text { stress }\end{array}$ & 20.52 & 2820 & 20.16 & 3070 \\
\hline & $\begin{array}{c}\text { Level } 1 \text { Pre- } \\
\text { stress }\end{array}$ & 21.63 & 3340 & 20.16 & 3070 \\
\hline & $\begin{array}{c}\text { Level } 1 \text { Pre- } \\
\text { stress }\end{array}$ & 20.22 & 1766 & 20.16 & 3070 \\
\hline
\end{tabular}

